\title{
Soil Microbiomes Associated with Verticillium Wilt-Suppressive Broccoli and Chitin Amendments are Enriched with Potential Biocontrol Agents
}

\author{
Patrik Inderbitzin, Judson Ward, Alexandra Barbella, Natalie Solares, Dmitriy Izyumin, \\ Prabir Burman, Dan O. Chellemi, and Krishna V. Subbarao ${ }^{\dagger}$
}

First and eighth authors: Department of Plant Pathology, and fifth and sixth authors: Department of Statistics, University of California, Davis; and second, third, fourth, and seventh authors: Driscoll's Strawberry Associates, Watsonville, CA.

Accepted for publication 31 August 2017.

\begin{abstract}
Two naturally infested Verticillium wilt-conducive soils from the Salinas Valley of coastal California were amended with disease-suppressive broccoli residue or crab meal amendments, and changes to the soil prokaryote community were monitored using Illumina sequencing of a $16 \mathrm{~S}$ ribosomal RNA gene library generated from 160 bulk soil samples. The experiment was run in a greenhouse, twice, with eggplant as the Verticillium wilt-susceptible host. Disease suppression, plant height, soil microsclerotia density, and soil chitinase activity were assessed at the conclusion of each experiment. In soil with high microsclerotia density, all amendments significantly reduced Verticillium wilt severity and microsclerotia density, and increased soil chitinase activity. Plant height was increased only in the broccoli-containing treatments. In total, 8,790 error-corrected sequence variants representing 1,917,893 different sequences were included in the analyses. The treatments had a significant impact on the soil microbiome community structure but

measures of $\alpha$ diversity did not vary between treatments. Community structure correlated with disease score, plant height, microsclerotia density, and soil chitinase activity, suggesting that the prokaryote community may affect the disease-related response variables or vice versa. Similarly, the abundance of 107 sequence variants correlated with disease-related response variables, which included variants from genera with known antagonists of filamentous fungal plant pathogens, such as Pseudomonas and Streptomyces. Overall, genera with antifungal antagonists were more abundant in amended soils than unamended soils, and constituted up to $8.9 \%$ of all sequences in broccoli+crabmeal-amended soil. This study demonstrates that substrate-mediated shifts in soil prokaryote communities are associated with the transition of Verticillium wilt-conducive soils to Verticillium wilt-suppressive soils, and suggests that soils likely harbor numerous additional antagonists of fungal plant pathogens that contribute to the biological suppression of plant disease.
\end{abstract}

Verticillium wilt is a fungal vascular wilt disease affecting a variety of hosts in different regions of the world (Pegg and Brady 2002). The disease is caused by species of Verticillium (Inderbitzin et al. 2011), of which Verticillium dahliae has the widest host range and geographic distribution, but other species are also important (Inderbitzin and Subbarao 2014). Verticillium wilt causes heavy losses of high-value crops, including cotton (Friebertshauser and DeVay 1982), lettuce (Atallah et al. 2011; Subbarao et al. 1997), potato (Rowe and Powelson 2002), and strawberry (Wilhelm and Paulus 1980). Once established, V. dahliae is difficult to eliminate due to microsclerotia, which are heavily melanized resting structures that can lay dormant in the soil for more than 10 years (Wilhelm 1955).

In the Pajaro and Salinas Valleys of coastal California, Verticillium wilt seriously affects the production of the two most economically important crops, strawberry and lettuce (Anonymous 2016a,b). Disease management has relied principally upon soil fumigation (Atallah et al. 2011; Wilhelm and Paulus 1980). However, the most effective fumigant, methyl bromide, is no longer available and other fumigants face increasing regulatory and public scrutiny due to human health and environmental concerns (Duniway 2002; White 2013).

Beneficial soil amendments have been part of agriculture for millennia (Bailey and Lazarovits 2003), and their effectiveness

†Corresponding author: K. V. Subbarao; E-mail: kvsubbarao@ucdavis.edu

*The $\boldsymbol{e}$-Xtra logo stands for "electronic extra" and indicates that nine supplementary documents are published online.

This article is in the public domain and not copyrightable. It may be freely reprinted with customary crediting of the source. The American Phytopathological Society, 2018. against Verticillium wilt was demonstrated decades ago (Haenseler 1928; Wilhelm 1951). The most widely used organic soil amendment in the Salinas Valley is broccoli residue which, upon incorporation into the soil, reduces microsclerotia density and Verticillium wilt incidence and severity (Njoroge et al. 2009; Xiao et al. 1998). Broccoli rotation as a means to managing Verticillium wilt has been widely embraced by the agricultural industry and, despite its low economic returns, broccoli is now among the top crops by hectarage in the Salinas Valley (Anonymous 2016a). However, when incorporated alone, broccoli rotation does not achieve the same level of disease control and microsclerotia reduction as soil fumigation with methyl bromide-chloropicrin mixtures (Subbarao et al. 2007).

Chitin-containing soil amendments derived from byproducts of the seafood industry, including crab, lobster, and shrimp shells, are another disease management option for $V$. dahliae and other soilborne pathogens (Sharp 2013). Chitin amendments mitigate the impact of soilborne diseases, including Fusarium yellows (Bell et al. 1998a) and Verticillium wilt (Cretoiu et al. 2013; Dutta and Isaac 1979; Jordan et al. 1972; Korthals et al. 2014), and plantparasitic nematodes, including Meloidogyne spp. (RodriguezKabana et al. 1987; Spiegel et al. 1986). Suppression of Verticillium wilt with chitin-containing amendments has not been demonstrated in soils from the coastal valleys of California but was effective in reducing the severity of Fusarium yellows of celery (Bell et al. 1998a).

A potential contribution of soil microbiomes in amendmentmediated suppression of Verticillium wilt was proposed in the 1950s (Wilhelm 1951), and there is evidence that disease-suppressive effects of broccoli and chitin involve a microbial component. Broccoli and other Brassica crops produce glucosinolates whose breakdown products are toxic for V. dahliae and other fungi (Mayton et al. 1996; Tierens et al. 2001). However, lignin extracted from 
broccoli and other crops and added to the soil reduces microsclerotia density without glucosinolates (Debode et al. 2005). Lignin is thought to promote the growth of lignin degraders (Shetty et al. 2000), some of which can also degrade fungal melanin (Butler and Day 1998). Thus, because melanin encapsulates the walls of microsclerotia (Wheeler et al. 1976), lignin degraders may reduce the viability of microsclerotia. A decrease in soil microsclerotia density was also shown for other plant-based amendments, including alfalfa, oat residues (Green and Papavizas 1968), green clover, and wheat straw (Jordan et al. 1972), with an accompanying reduction in Verticillium wilt severity demonstrated for alfalfa (Dutta and Isaac 1979). Similarly, chitin is a structural polysaccharide found in the cell walls of fungal hyphae and nematode eggs, and chitin-mediated changes in soil and rhizosphere bacterial communities have been demonstrated in the presence of Verticillium spp. (Cretoiu et al. 2013; Dutta and Isaac 1979; Jordan et al. 1972) and without Verticillium spp. (Cretoiu et al. 2014; Hallmann et al. 1999; Jacquiod et al. 2013). Addition of chitin to soil results in a shift toward Actinobacteria (Cretoiu et al. 2013; Dutta and Isaac 1979; Jordan et al. 1972) and the family Oxalobacteraceae (Cretoiu et al. 2013), both capable of degrading chitin (Cretoiu et al. 2013), and an overall increase in the number of chitinase genes (Cretoiu et al. 2013). Also, chitin stimulates the antagonistic activity of Bacillus spp. and Trichoderma harzianum (Ahmed et al. 2003). Taken together, this evidence suggests that the disease-reducing effect of broccoli and chitin-based soil amendments is mediated, at least in part, by enzymatic activity against $V$. dahliae.

Soil amendments have been an active area of research for many years, and numerous reviews summarize various aspects of earlier work on soil amendments and microbial populations (Bailey and Lazarovits 2003; Bonanomi et al. 2010; Garbeva et al. 2004; Hoitink and Boehm 1999; Weller et al. 2002). Changes in soil microbiomes based on high-throughput DNA sequencing were described for different land management practices (Chellemi et al. 2012), as well as for individual organic amendments, including almond shells (Vida et al. 2016), Brassica seed meal (Mazzola et al. 2015), chitin (Debode et al. 2016; Jacquiod et al. 2013), or rice bran (Tomihama et al. 2016). Taxa with increased abundance following amendments include several bacterial genera that contain known antagonists of fungal plant pathogens, including Bacillus (Chaiharn et al. 2009; Tomihama et al. 2016), Rhodococcus (Mazzola et al. 2015; Renwick et al. 1991), and Streptomyces (Coombs et al. 2004; Debode et al. 2016). However, it is unknown whether antagonistic bacteria as a whole are significantly more abundant in amended soil compared with controls, and whether antifungal antagonists are the largest and, thus, potentially most important group of bacteria for disease reduction in amended soil. Several mechanisms through which antagonistic bacteria suppress fungal plant pathogens have been described (Lugtenberg and Kamilova 2009), and those mechanisms likely also play a part in reducing Verticillium wilt severity by the broccoli and crabmeal amendments.

The goal of this work was to describe the prokaryote community structure of broccoli and crabmeal-amended soils and to measure their association with Verticillium wilt. We performed greenhouse experiments with two types of microsclerotia-infested agricultural field soils with eggplant as the susceptible host, and measured Verticillium wilt severity, plant height, microsclerotia density, and soil chitinase activity. The prokaryote community structure of bulk soil was assessed using high-throughput DNA sequencing of a $16 \mathrm{~S}$ ribosomal RNA polymerase chain reaction (PCR) amplicon library. We hypothesized that (i) the broccoli and crabmeal amendments reduce Verticillium wilt severity; (ii) amendments affect the community structure of the soil microbiome; (iii) potential antagonists of fungal plant pathogens are enriched in amended soils compared with unamended soils and, thus, may play a role in disease reduction; and (iv) the abundance of some species correlates with disease score, plant height, microsclerotia density, or soil chitinase activity, suggesting a link between species abundance and disease-relevant response variables.

\section{MATERIALS AND METHODS}

Soils used and soil characterization. Soils were collected from two Salinas Valley, CA, locations with different soil types. Both locations have a history of intense strawberry-lettuce-lettucelettuce rotations, preplant soil fumigation with methyl bromide and chloropicrin, and severe Verticillium wilt epidemics. Ranch A soil, designated as soil A, was collected on 19 February 2014 from an area planted to strawberry in 2013 but not fumigated due to buffer zone restrictions. Microsclerotia density of soil A was 27.5 microsclerotia/g of soil (Supplementary Document S1). Ranch B soil ( soil B) was collected on 30 October 2013 from an area that was last fumigated in September 2012 with a drip-applied formulation of chloropicrin and 1,3-dichloropropene. Soil B microsclerotia density was 1.2 microsclerotia/g of soil. Soil was stored in plastic bins indoors for later use. Physicochemical soil characteristics were determined by Perry Laboratory, Watsonville, CA, for unamended soil A and soil B sampled on 27 May 2014 prior to planting eggplant. Soil $\mathrm{pH}$ was measured on a saturated paste and electrical conductivity was measured on the extract from the saturated paste. The cation exchange capacity was analyzed by barium rinse followed by calcium replacement. Details of soil ion content are given in Supplementary Document S2. Soil microsclerotia densities were determined using an Anderson spore trap, as described by Kabir et al. (2004). Soil chitinase activity was determined by Glades Crop Care, Jupiter, FL, as described by Parham and Deng (2000).

Soil treatments. Soil amendments used were broccoli and crabmeal. Broccoli leaves were collected from mature plants on ranch B on 17 April 2014 and stored at $5^{\circ} \mathrm{C}$. Crabmeal was ground crab shell containing $10 \%$ feather meal (wt/wt), and was obtained as Crab Life from Agricultural Solutions, LLC, Safety Harbor, FL.

Soil A and soil B containing perlite for drainage (0.24 liter of perlite per $2.6 \mathrm{~kg}$ of soil) were amended with broccoli leaf slices of approximately $1 \mathrm{~cm}$ in diameter (10\% fresh weight of broccoli/dry weight of soil) or crabmeal $(0.2 \% \mathrm{wt} / \mathrm{wt})$. A broccoli soil amendment rate of $10 \%$ reflects the approximately 224 metric tons of broccoli residue per hectare remaining in the field after harvest. A $0.2 \%$ crabmeal amendment rate corresponds to $4,480 \mathrm{~kg} / \mathrm{ha}$. A concrete mixer was used for blending soil with the different amendments. The mixer was washed thoroughly between treatments.

Plant hosts. Eggplant (Solanum melongena L.) was used as indicator for Verticillium wilt disease severity because of its high susceptibility to $V$. dahliae and ease of handling. Cultivar Early Long Purple (Eden Brothers, Asheville, NC) seed were planted into 128-plug trays using steam-sterilized Sunshine Basic Mix number 2 potting mix (Sun Gro Horticulture, Agawam, MA), watered and fertilized daily, and grown for 2 weeks.

Experimental design. The experiment was set up as a randomized complete block design in a greenhouse with four amendment levels, including a control, and two soil types, with five replicates of each amendment-soil type combination. The experiment was performed twice, and the two repetitions were considered to be independent. Amendment levels were no amendment, broccoli residue (10\% fresh weight/dry soil weight), crabmeal $(0.2 \%$ dry weight/dry soil weight), and broccoli residue plus crabmeal (10 and $0.2 \%$, respectively). After the first repetition, soil from each treatment was reused to simulate a repeated monoculture in the field. Experimental units consisted of 3.8-liter pots, each containing three eggplant seedlings.

Experimental setup. The experiment was performed in a greenhouse at the United States Department of Agriculture Research Station in Salinas, CA, and was initiated on 28 April 2014, when amended soil was prepared and filled into 9 or 103.8 -liter pots per treatment (Fig. 1). At time point 1 (27 May), eggplant seedlings were transplanted into the pots and bulk soil was sampled from five randomly sampled pots of each treatment (Fig. 1). At time point 2 (28 to 31 July), Verticillium wilt symptoms on eggplant seedlings and seedling heights were assessed for the pots sampled at time 
point 1 , and bulk soil samples were taken from the same pots for microbiome characterization and determination of microsclerotia density and soil chitinase activity. For the second repetition, soil from the first repetition was pooled for each treatment and amendments were reintroduced on 9 September. Time points 1 and 2 for the second repetition corresponded to 30 September and 3 December, respectively.

Disease evaluation. Plants were removed from pots, rinsed free of soil, and cut longitudinally through the center of taproot and crown. Disease severity was assessed by a combination of tap root vascular discoloration and foliar symptoms, including wilting and angular regions of chlorosis and necrosis along leaf margins (Vallad et al. 2006). Disease severity was rated on a scale of 0 to 5 , in which $0=$ no vascular discoloration; $1=1$ to $25,2=26$ to $50,3=51$ to 75 , and $4=76$ to $100 \%$ of vascular tissues in the tap root discolored with foliar symptoms; and $5=100 \%$ discoloration but with severely stunted or dead plants. Plant height was also measured from the crown to tip. Disease scores and plant heights were averaged across three plants for each experimental unit.

Soil sampling. Bulk soil was taken from pots, visible plant material was removed, and approximately $100 \mathrm{~g}$ of soil was placed in a sterile plastic bag and stored at $4^{\circ} \mathrm{C}$ for less than $72 \mathrm{~h}$ prior to DNA extraction and initiation of microsclerotia density and chitinase activity assessment.

DNA extraction. Soil DNA was extracted with the Power Soil DNA Isolation Kit (MO BIO Laboratories, Inc., Carlsbad, CA) using $0.25 \mathrm{~g}$ of soil per extraction and following the manufacturer's instructions, with the following changes. A tissue lyser was used at $1,400 \mathrm{rpm}$ for $3 \mathrm{~min}$ instead of a vortex at mixing step 2. A 30 - to 45min waiting step was added to elution step 20. Large debris was removed from soil manually before extraction. DNA purity was assessed with a NanoDrop spectrophotometer (Thermo Scientific, Wilmington, DE), and DNA concentration was adjusted to $2 \mathrm{ng} / \mu \mathrm{l}$.

PCR and sequencing. We targeted the archaeal and bacterial V3/V4 16S ribosomal region for PCR and sequencing. Procedures were according to the Illumina 16S Metagenomic Sequencing Library Preparation Instructions (part number 15044223 Rev. A; https://www.illumina.com/content/dam/illumina-marketing/documents/ products/appnotes/16S-Metagenomic-Library-Prep-Guide.pdf) with primers Bakt_341F and Bakt_805R (Herlemann et al. 2011; Klindworth et al. 2012) and the following changes. Input DNA concentration was lowered from 5 to $2 \mathrm{ng} / \mu \mathrm{l}$; PCR 1 master mix composition was $0.5 \mu \mathrm{l}$ of water, $2 \mu \mathrm{l}$ of input DNA, $12.5 \mu \mathrm{l}$ of Taq $2 \times$ Master Mix (New England Biolabs, Inc., Ipswich, MA), $5 \mu$ of $16 \mathrm{~S}$ forward primer $(2.5 \mu \mathrm{M})$, and $5 \mu \mathrm{l}$ of $16 \mathrm{~S}$ reverse primer $(2.5 \mu \mathrm{M})$; the number of PCR cycles in the amplicon PCR step was increased from 25 cycles to 30 cycles; during the library denaturation and MiSeq sample loading step, pooled samples were diluted to 16 to $20 \mathrm{pM}$; diluted and denatured libraries were spiked with $10 \% 16$ to $20 \mathrm{pM}$ single-stranded DNA PhiX control. Libraries were sequenced on an Illumina MiSeq DNA sequencer (Illumina Inc., San Diego, CA) in Driscoll's in-house sequencing lab with $2 \times$ 300 cycles using the v3 reagent kit. MiSeq Control Software (v. 2.6.1.1; Illumina Inc.) ran with the following settings: remove read 1 adapter, remove read 2 adapter, and output FASTQ files only. Samples were sequenced on three different days.

Data analyses and statistics. Data analyses were performed in R, version 3.3.3, with RStudio 1.0.44 (R Core Team 2015, 2017) or on the Mac OS X command line with MacQIIME 1.9.1-20150604 (http://www.wernerlab.org/software/macqiime), a precompiled installation of QIIME. R packages for data manipulation and plotting included dplyr 0.5.0 (Wickham and Francois 2016), ggplot2 2.1.0 (Wickham 2009), plyr 1.8.4 (Wickham 2011), and tydr 0.5.1 (Wickham 2016). All code used for data analyses is provided in Supplementary Document S3).

The impact of amendment on the response variables disease score, plant height, microsclerotia density, and soil chitinase activity was evaluated using multivariate analysis of variance
(MANOVA) (formula: response variable $\sim$ amendment + soil type + sampling date + blocking factor), followed by the Tukey's honestly significant difference post hoc test, performed in $\mathrm{R}$ with packages agricolae 1.2-4 (de Mendiburu 2016), car 2.1-4 (Fox and Weisberg 2011), lattice 0.20-34 (Sarkar 2008), and Rmisc 1.5 (Hope 2013). For soil A, two outliers, defined as data values larger than the third quartile by at least 1.5 times the interquartile range, were excluded from the respective analyses. The outliers were sample S174, with 80 microsclerotia $\mathrm{g}^{-1}$ of soil, and sample S1272, with a chitinase activity of PNP (4-nitrophenyl $\mathrm{N}$-acetyl- $\beta$-D-glucosaminide) at $195 \mathrm{mg} \mathrm{kg}^{-1}$ of soil. Exclusion of the two data values had no material effect on the results or conclusions.

Demultiplexed paired-end reads with barcodes removed were obtained from the sequencing facility. Primer sequences were trimmed with QIIME script multiple_extract_barcodes.py. The reads were passed to DADA2 1.2.2 (Callahan et al. 2016), where 25 and 100 low-quality positions from the 3 ' end of forward and reverse reads, respectively, were trimmed, followed by quality filtering, dereplication, sample inference, paired read merging, and chimera identification using default settings. Taxonomy was assigned to the DADA2-inferred sequences with QIIME's assign_ taxonomy.py based on the Greengenes taxonomy and reference database release 13_8 (McDonald et al. 2012; Werner et al. 2012), with UCLUST as the taxon assignment method (Edgar 2010). Chloroplast, mitochondrial, unalignable, and unassigned sequences were removed prior to analyses. Five samples with fewer than 1,000 sequences (S170, S180, S359, S828, and S1247) were excluded from analyses, resulting in a 152-sample dataset.

Differential abundance testing for taxonomic phyla between broccoli+crabmeal, broccoli, and crabmeal treatments with respect to controls was performed in DESeq2 1.14.1 (Love et al. 2014) (formula: sequence count $\sim$ amendment + soil type + sampling date + blocking factor). Sequence counts for individual phyla for testing were obtained with QIIME's summarize_taxa.py. Only the top five most abundant phyla based on uncorrected sequence proportions were included in differential abundance testing. $P$ values were BenjaminiHochberg corrected for multiple comparisons.

Differences between amendment treatments in the proportion of sequences belonging to genera containing antagonists of filamentous fungal plant pathogens for both soil types combined were investigated with Welch's analysis of variance (ANOVA), which is appropriate when variances are unequal and the experimental design is unbalanced (formula: sequence proportion $\sim$ amendment). Post hoc evaluation was done by Tukey's all-pair comparisons with a Bonferroni-Hochberg correction for multiple comparisons, using the glht function of multcomp 1.4-6. Code was based on Mangiafico (2015). DESeq2 normalized sequence counts were used, which were generated with QIIME's normalize_table.py.

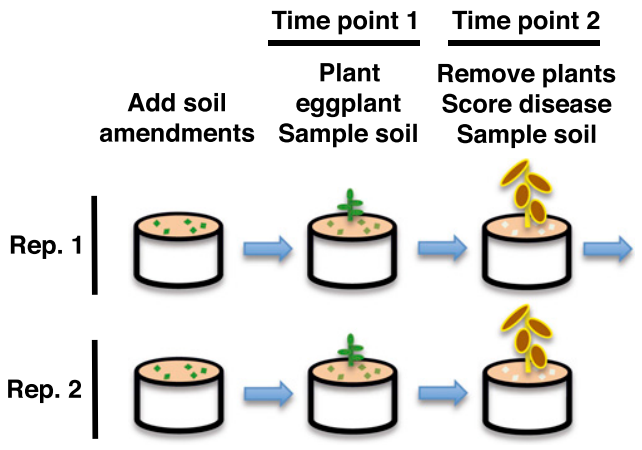

Fig. 1. Sequential progression of activities performed during the experiment. The experiment was repeated twice. At time point 2, disease severity, plant height, microsclerotia density, and soil chitinase activity were assessed. Rep. $=$ repetition. 
The $\alpha$ diversity calculations for communities defined by amendment were performed in R package phyloseq 1.16.2 (McMurdie and Holmes 2013) using observed numbers of sequences and Shannon Index measures of diversity based on data rarefied to 1,000 sequences per sample. Results were plotted in ggplot2. MANOVA to assess the impact of amendment type on the two $\alpha$ diversity metrics were performed as described above.

Ordination plots of sample populations were generated using phyloseq. Samples were transformed to equal sample sum by proportional transformation and the unweighted UniFrac distance measure (Lozupone and Knight 2005) was used for principal coordinate analysis (PCoA). A phylogenetic tree required for the UniFrac distance measure was constructed with QIIME's make_ phylogeny.py using FastTree 2.1.3 (Price et al. 2010), and the underlying DNA sequence alignment was generated with QIIME's align_seqs.py against the Greengenes Core reference alignment (DeSantis et al. 2006) using PyNAST (Caporaso et al. 2010). Significance of sample groupings defined by amendment, replicate, time point, and soil type was assessed using permutational MANOVA with QIIME script compare_categories.py that invoked the adonis function from $\mathrm{R}$ package vegan 2.4-0 (Oksanen et al. 2016) with 999 permutations, and used unweighted UniFrac distances inferred from data rarefied to 1,000 sequences per sample. Rarefaction was performed with QIIME script single_ rarefaction.py.

The relationships of population structure to response variables were evaluated by investigating the correlation of the unweighted UniFrac distance-based PCoA axis 3 coordinates from time point 2 with disease scores, plant height, microsclerotia density, and chitinase activity, respectively (formula: PCoA axis 3 coordinate response variable). For soil A, two outliers were excluded from the respective analyses: sample $\mathrm{S} 174$, with 80 microsclerotia $\mathrm{g}^{-1}$ of soil, and sample S1272, with a chitinase activity of PNP at $195 \mathrm{mg} \mathrm{kg}^{-1}$ of soil.

Differential sequence variant abundance testing between broccoli+ crabmeal-, broccoli-, and crabmeal-amended soil and unamended soil was performed separately for soil A and soil B at each of the two time points with DESeq2 (formula: sequence variant count $\sim$ amendment + replicate + blocking factor). Only the 399 variants that were each found more than 959 times $(>0.05 \%$ of total number of sequences) were included for testing.

Correlations between sequence variant abundance and disease score, plant height, microsclerotia density, and soil chitinase activity were investigated for the 86 and 83 variants that were more abundant in amended soils as compared with untreated soil at time points 1 and 2, respectively. Samples were rarefied to 1,000 sequences per sample with QIIME script single_rarefaction.py, and

TABLE 1. Summary of tests performed

\begin{tabular}{ll}
\hline Null hypothesis & Conclusion \\
\hline $\begin{array}{l}\text { Soil amendments do not affect disease score, plant } \\
\text { height, microsclerotia density, or soil chitinase activity }\end{array}$ & Rejected \\
$\begin{array}{l}\text { Abundance of taxonomic phyla is not affected by soil } \\
\text { amendments }\end{array}$ & Rejected \\
$\begin{array}{l}\text { Abundance of antagonistic genera is not affected by soil } \\
\text { amendments }\end{array}$ & $\begin{array}{l}\text { Rejected } \\
\alpha \text { Diversity is identical in all amendment treatments }\end{array}$ \\
$\begin{array}{l}\text { Prokaryote population structure is not affected by soil } \\
\text { type, experimental replicate or time point }\end{array}$ \\
$\begin{array}{l}\text { Prokaryote population structure does not correlate with } \\
\text { disease score, plant height, microsclerotia density, or } \\
\text { chitinase activity }\end{array}$ & Rejected \\
$\begin{array}{l}\text { Abundance of sequence variants is not affected by soil } \\
\text { amendments }\end{array}$ & Rejected \\
$\begin{array}{l}\text { Abundance of sequence variants does not correlate with } \\
\text { disease score, plant height, microsclerotia density, or } \\
\text { chitinase activity }\end{array}$ & Rejected \\
\hline
\end{tabular}

Spearman's rank-order correlation was determined with QIIME's observation_metadata_correlation.py.

\section{RESULTS}

A summary of the scientific questions and conclusions is shown in Table 1; details are provided below.

Impact of amendment on Verticillium wilt severity, plant height, soil chitinase activity, and microsclerotia density. Amendment had a significant impact on disease score, plant height, microsclerotia density, and soil chitinase activity $(P \leq 0.004)$ (for complete ANOVA result tables, see Supplementary Document S4). The data were analyzed separately for soil A and soil B because the interaction between amendment and soil type was significant for disease score and microsclerotia density $\left(P \leq 2.0 \times 10^{-04}\right.$; data not shown). In soil A, all amendments reduced disease score and microsclerotia density equally with respect to the control. Plant height was only increased by the broccoli+crabmeal and broccoli treatments, and soil chitinase activity was increased by all amendments (Fig. 2). In soil B, microsclerotia density was increased in the crabmeal treatment and soil chitinase activity was increased for all amendments (Fig. 2).

Read, sequence, and sequence variant counts. In total, $27,466,136$ paired-end reads were obtained from 157 of the 160 samples collected with read lengths of $299.2 \pm 6.2$ bp (mean \pm standard deviation). From the reads, DADA2 (Callahan et al. 2016) inferred 9,996 unique, error-corrected, nonchimeric sequence variants representing 2,164,258 sequences. After removal of chloroplast, mitochondria, unalignable and unassigned variants, and variants only present in the excluded samples, 8,790 variants representing 1,917,893 sequences remained, and were used for analyses. The sequences measured $417 \pm 11$ bp (mean \pm standard deviation).

Raw sequence data were deposited in the National Center for Biotechnology Information Sequence Read Archive (https://www. ncbi.nlm.nih.gov/sra) under the accession number SRP115328.

Taxonomic diversity and abundance across samples. Sequences belonged to 38 archaeal and bacterial phyla. The top five phyla overall by relative abundance were the Proteobacteria, accounting for $44.1 \%$ of all sequences, followed by Actinobacteria (13.9\%), Bacteroidetes (11.3\%), Firmicutes (6.5\%), and Acidobacteria $(5.0 \%)$ (Fig. 3). The Actinobacteria were more abundant in broccoli+crabmeal- and crabmeal-amended soil than in the control $\left(P \leq 1.0 \times 10^{-03}\right)$, and the Proteobacteria were more abundant in broccoli-amended soil than in the control $(P=7.6 \times$ $\left.10^{-03}\right)$. The Acidobacteria were less abundant in any of the amended soils than in the control $\left(P \leq 1.6 \times 10^{-02}\right)$, the Bacteroidetes were less abundant in the broccoli+crabmeal- and the crabmeal-amended soils than in the control $\left(P=8.8 \times 10^{-04}\right)$, and the Firmicutes were less abundant in the crabmeal-amended soil than in the control $\left(P=1.4 \times 10^{-02}\right)$. The top five genera by relative abundance were Kaistobacter and Bacillus, with $4.9 \%$ of total sequences each, followed by Cellvibrio (2.6\%), Streptomyces (2.5\%), and Arthrobacter (2.2\%).

Proportion of sequences related to antagonists of filamentous fungal plant pathogens. We found evidence of antagonism against filamentous fungal plant pathogens for 47 of the 300 genera in this study (Table 2). The proportion of sequences belonging to antagonistic genera varied significantly between amendment treatments $\left(P=8.91 \times 10^{-15}\right)$, from an average of $8.9 \%$ in broccoli+ crabmeal-amended soil to $7.4 \%$ in unamended soil. All amended soils contained significantly more sequences from antagonistic genera than unamended soil (Fig. 4). Soil A and soil B samples were combined for the analyses because we were interested in the overall impact of the amendments on antagonistic genera.

$\alpha$ Diversity of communities defined by amendment. The mean observed number of sequence variants varied from 207 in the 
control to 234 in crabmeal-amended soil, and the Shannon Index mean value varied from 4.70 in broccoli to 4.89 in crabmealamended soil, both at a rarefaction level of 1,000 sequences per sample. None of the differences were significant $(P>0.05)$ (Fig. 5). The impact of amendment, blocking factor, sampling time point, and soil type were not significant $(P \geq 0.32)$. For complete ANOVA results, see Supplementary Document S5.

Experimental variables and community structure. Soil type and amendment affected the bulk soil prokaryote community similarly regardless of experimental replicate and sampling time point. The samples were separated by soil type along PCoA axis 2 , and were arranged by amendment in a gradient from control to broccoli+crabmeal samples along axis 3 (Fig. 6). This pattern was independent of the day the samples were sequenced and, thus, is not due to technical error (Supplementary Document S6). The experimental variables amendment, soil type, replicate, and time point all significantly affected population structure (adonis $P<$ $0.001)$.

Correlation of population structure with response variables. The correlation between response variables and population structure represented by PCoA axis 3 coordinates was investigated separately for the two soil types. For soil A, the correlations between disease score, plant height, microsclerotia density, and chitinase activity with $\mathrm{PCoA}$ axis 3 coordinates were significant $(P \leq 0.023)$ (Fig. 7). For soil $\mathrm{B}$, only microsclerotia density $(P=0.004)$ and chitinase activity $(P=0.022)$ correlated significantly with PCoA axis 3 coordinates (data not shown). The $R^{2}$ values were moderate to low (Fig. 7).

Differential sequence abundance between amended and unamended soils. Differential abundance of sequence variants was investigated between amended soils and controls at time points
1 and 2, separately for soil A and soil B (Fig. 8; Supplementary Document S7). In total, 199 variants were differentially abundant. The number of differentially abundant variants ranged from two for the crabmeal-control comparison in soil B at time point 2 to 78 for

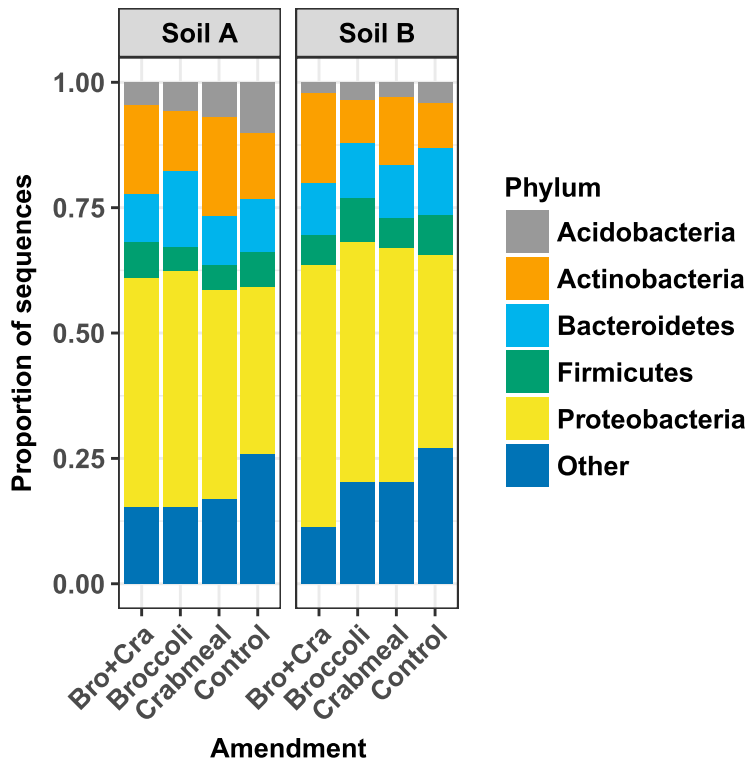

Fig. 3. Stacked bar graph showing proportion of sequences in different phyla for treatments and soil types. Only the top five most abundant phyla are shown; the remaining sequences are pooled under "Other". Soil type is indicated in panel header. Colors represent phyla and are explained in the legend; Bro+Cra $=$ broccoli+crabmeal. Number of sequences: $n=1,917,893$.
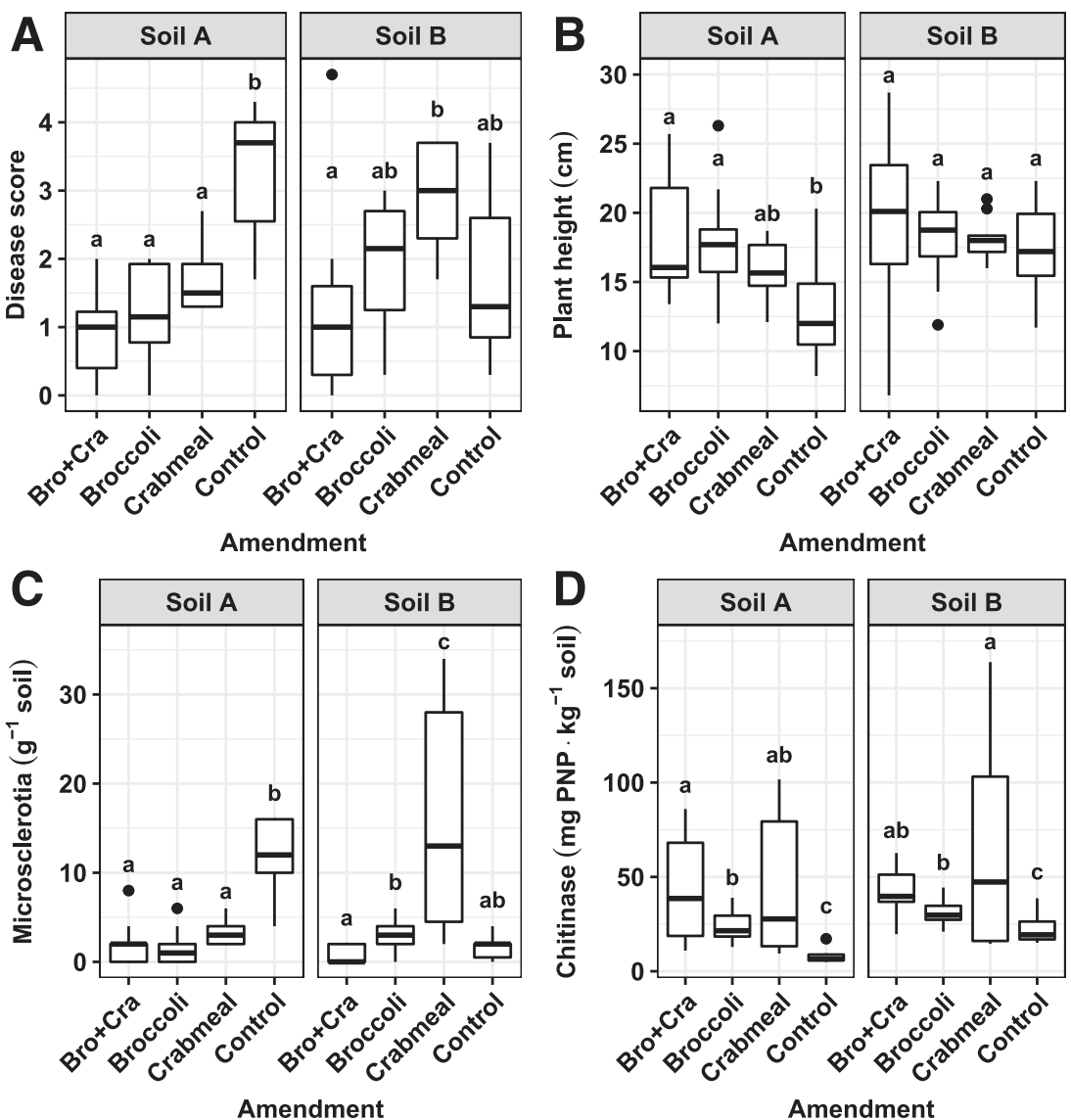

Fig. 2. Boxplots showing A, disease scores; B, plant height; $\mathbf{C}$, microsclerotia density; and $\mathbf{D}$, soil chitinase activity for the different treatments in soil A and soil B measured at time point 2. Significance is indicated by lowercase letters, different letters show significance between treatments within each soil type (Tukey's honestly significant difference $P<0.05$ ). Bro+Cra $=$ broccoli+crabmeal. Number of observations: for $\mathrm{A}$ and $\mathrm{B}, n=160$, and for $\mathrm{C}$ and $\mathrm{D}, n=159$. 
the broccoli-control comparison in soil A at time point 1. The sets of differentially abundant variants differed between comparisons. The only variants that were more abundant in amended soils in all comparisons were six variants of Achromobacter and two variants of Streptomyces. No variants were enriched in all controls. In soil A, 37 variants were enriched in amended soils in all comparisons; the variants belonged to genera Achromobacter, Bacillus, Balneimonas, Devosia, Hydrogenophaga, Nannocystis, Phenylobacterium, Pseudomonas, Pseudoxanthomonas mexicana, Sphingomonas, and Streptomyces and four unknown genera. Only two variants of Nitrospora were consistently enriched in the controls in soil A. For similar details of soil B, see Supplementary Document S8. The Streptomyces variant designated as Streptomyces sp. 9 had the highest absolute abundance among amendment-enriched variants and accounted for $3.6 \%$ of all sequences at time point 1 of broccoli+ crabmeal-amended soil B. The Pseudomonas variant Pseudomonas sp. 10 was the most amendment-enriched variant, and was nearly 2,000 times more abundant at time point 1 in broccoli+crabmealamended soil B than in untreated soil. Among amendment-enriched variants, $32 \%$ of all variants fell into genera containing antifungal antagonists, and $34 \%$ were not assigned to any known genera.
Correlation of sequence abundance with response variables. The abundance of 107 different sequence variants correlated with disease severity, plant height, microsclerotia density, or soil chitinase activity (Supplementary Document S9). Among the 86 variants that were amendment enriched at time point 1 , the abundance of 12,21 , 22 , and 71 of the variants correlated with microsclerotia density, disease severity, plant height, and chitinase activity, respectively $(P<$ 0.05 , with Benjamini-Hochberg correction for multiple comparisons) (Fig. 9). Among the 83 variants that were amendment-enriched at time point 2 , none of the variants were correlated with disease severity and microsclerotia density, 21 correlated with plant height, and 22 with chitinase activity. Soil A and soil B samples were combined for the analyses to increase statistical power.

\section{DISCUSSION}

Soil amendments are beneficial for management of soilborne diseases but are generally less effective and less economical than chemical alternatives (Chellemi and Lazarovits 2002; Lazarovits and Subbarao 2009; Subbarao et al. 2007). The interactions among

TABLE 2. Genera containing antagonists of filamentous fungal plant pathogens

\begin{tabular}{|c|c|c|}
\hline Genus & Mechanism $^{\mathrm{a}}$ & Reference \\
\hline Achromobacter & Siderophores & Moretti et al. (2008) \\
\hline Acidovorax & Unknown & Yang et al. (2008) \\
\hline Acinetobacter & Antibiotics & Cordero-Ramírez et al. (2013); Liu et al. (2007) \\
\hline Actinomadura & Antibiotics & Kim et al. (2000) \\
\hline Actinoplanes & CWDE, parasitism & El-Tarabily (2003); El-Tarabily et al. (1997) \\
\hline Arthrobacter & CWDE & Morrissey et al. (1976) \\
\hline Azospirillum & Induced resistance, siderophores & Tortora et al. $(2011 \mathrm{a}, \mathrm{b})$ \\
\hline Bacillus & CWDE, siderophores & Cordero-Ramírez et al. (2013) \\
\hline Brachybacterium & Not determined & Mmbaga et al. (2008) \\
\hline Brevibacillus & Not determined & Chandel et al. (2010) \\
\hline Brevundimonas & Not determined & Berg et al. (2006) \\
\hline Burkholderia & Uncertain & McLoughlin et al. (1992) \\
\hline Chitinophaga & Not determined & Turnbull et al. (2012) \\
\hline Chryseobacterium & Not determined & Domenech et al. (2006); Yin et al. (2013) \\
\hline Comamonas & Antibiotics & Berg et al. (2001); El-Banna (2007) \\
\hline Cupriavidus & Pathogenicity factor degradation & Schoonbeek et al. (2007) \\
\hline Cytophaga & CWDE & Berg et al. (2001) \\
\hline Enterobacter & CWDE & Chernin et al. (1995) \\
\hline Exiguobacterium & Volatiles & Selvakumar et al. (2009) \\
\hline Flavobacterium & Not determined & Kwok et al. (1987) \\
\hline Haliangium & Antibiotics & Fudou et al. (2001); Kundim et al. (2003) \\
\hline Janthinobacterium & Protein degrading enzymes & Berg et al. (2001) \\
\hline Lysinibacillus & CWDE & Melnick et al. (2011) \\
\hline Lysobacter & Antibiotics & Li et al. (2008) \\
\hline Microbacterium & CWDE & Bibi et al. (2012); Pereira et al. (2007) \\
\hline Mycobacterium & CWDE & Bibi et al. (2012) \\
\hline Myxococcus & CWDE & Bull et al. (2002) \\
\hline Nannocystis & CWDE & Taylor and Draughon (2001) \\
\hline Nocardia & Not determined & Elson et al. (1997) \\
\hline Nocardioides & Not determined & Coombs et al. (2004) \\
\hline Nonomuraea & Not determined & Inderiati and Franco (2008) \\
\hline Oerskovia & Not determined & Sturz et al. (1998) \\
\hline Paenibacillus & CWDE & Chen et al. (2003) \\
\hline Pedobacter & Not determined & De Boer et al. (2007) \\
\hline Phormidium & Not determined & Alwathnani and Perveen (2014) \\
\hline Planococcus & Volatiles & Essghaier et al. (2009) \\
\hline Pseudomonas & CWDE, volatiles, siderophores & $\begin{array}{l}\text { Bibi et al. (2012); Elson et al. (1997); Erdogan and Benlioglu (2010); } \\
\text { Renwick et al. (1991); Thomashow and Weller (1988) }\end{array}$ \\
\hline Rhizobium & Induced resistance, antibiotics & Chakraborty and Chakraborty (1989); Chakraborty and Purkyastha (1984) \\
\hline Rhodococcus & Not determined & Renwick et al. (1991) \\
\hline Saccharothrix & Induced resistance & Muzammil et al. (2014) \\
\hline Solibacillus & Unknown & Melnick et al. (2011) \\
\hline Sphingobacterium & CWDE & Matsuda et al. (2001) \\
\hline Sphingomonas & Not determined & Adhikari et al. (2001) \\
\hline Stenotrophomonas & CWDE & Bibi et al. (2012) \\
\hline Streptomyces & CWDE, antibiotics, siderophores & Coombs et al. (2004); Mansoor et al. (2012); Renwick et al. (1991) \\
\hline Streptosporangium & Not determined & Lee and Hwang (2002) \\
\hline Virgibacillus & Volatiles & Essghaier et al. (2009) \\
\hline
\end{tabular}

a Mechanisms of antagonism are indicated. CWDE = cell-wall-degrading enzymes. 
disease suppression mechanisms in the soil, including soil and rhizosphere microbes, is complex and little understood and, thus far, may have prevented the development of competitive, organic alternatives. Here, we relate prokaryote community structure from broccoli- and crabmeal-amended soils inferred by high-throughput DNA sequencing to disease-related response variables, and speculate how amendment-induced communities may protect plants from Verticillium wilt.

We used broccoli and chitin-based amendments that are known to reduce Verticillium wilt severity and microsclerotia density (Chellemi et al. 2016; Cretoiu et al. 2013; Debode et al. 2005; Dutta and Isaac 1979; Subbarao et al. 1999), increase crop biomass (Debode et al. 2016; Subbarao et al. 1999), and promote soil chitinase activity in the case of chitin amendments (Jacquiod et al. 2013; Kielak et al. 2013) and observed results similar to those of previous studies. The absence of a significant impact of the amendments on disease severity in soil B may be due to the low level of microsclerotia present in soil B. There were only 1.2 microsclerotia/g of soil prior to amendment addition in soil B, as opposed to the $27.5 \mathrm{microsclerotia} / \mathrm{g}$ of soil in soil A. Maybe increasing the duration of the experiment would result in significant disease reduction in soil B, similar to that in soil A. Eggplant is very susceptible to Verticillium wilt and can show symptoms when microsclerotia density is only 1 microsclerotium/g of soil (Evans and McKeen 1975), which agrees with our study. We also found that microsclerotia density in crabmeal-treated soil B was elevated. This was unexpected and may have been caused by incomplete soil homogenization, because chitin amendments are not known to promote microsclerotia formation, and a comparable increase was not observed in soil A.

The microbial community structure was affected by amendment and soil type. This is illustrated by PCoA, which visualizes the relative affinities of the communities of individual samples. PCoA separated the samples more or less according to soil type along PCoA axis 2, and into broccoli+crabmeal and control samples along PCoA axis 3, with broccoli and crabmeal samples generally falling in between the broccoli+crabmeal and control samples. The withincommunity diversity ( $\alpha$ diversity) did not differ between amended soils, which is as previously observed in a chitin-amendment study

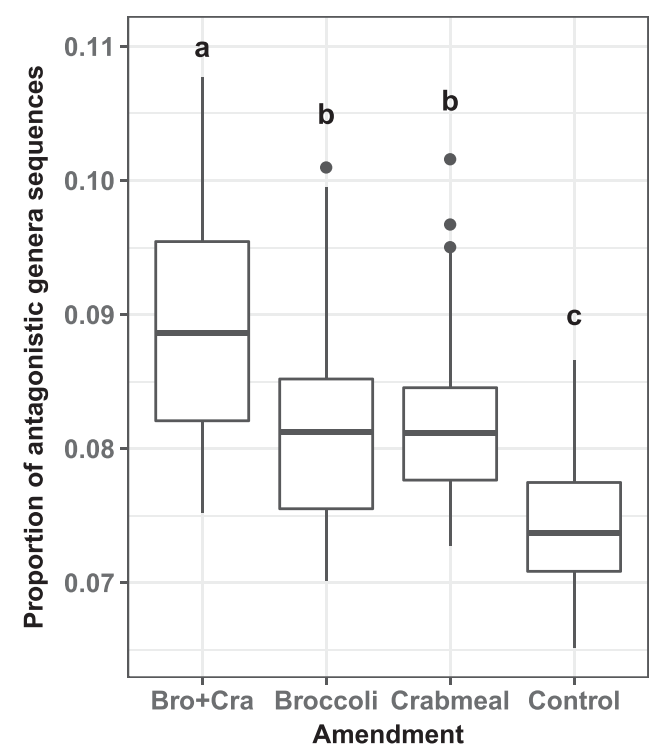

Fig. 4. Boxplot with proportions of sequences from genera containing antagonists of filamentous fungal plant pathogens in different treatments for both soil types combined. Treatment is indicated on the x-axis. Proportions are based on DESeq2 normalized sequence counts. Significance is represented by lowercase letters; different letters show significance between treatments (Tukey's all-pair comparisons $P \leq 7.39 \times 10^{-05}$, with Benjamini-Hochberg correction for multiple comparisons). Bro+Cra $=$ broccoli+crabmeal. Number of observations: $n=152$.
(Debode et al. 2016) but differed from a plant-based amendment study where Brassica seed meal added to the soil resulted in a decrease of rhizosphere diversity (Mazzola et al. 2015). Our $\alpha$ diversity measurements may have been biased by the reduced sample size due to rarefaction; therefore, future research should revisit this issue.

We investigated which of the taxonomic phyla and individual sequence variants differed in abundance between amended and unamended soils. The Actinobacteria were more abundant in crabmeal-containing soils as compared with unamended soil, and the Proteobacteria were enriched in broccoli-containing soil, as previously observed in plant-based (Mazzola et al. 2015) and chitinbased (Debode et al. 2016; Dutta and Isaac 1979; Henis et al. 1967; Jacquiod et al. 2013; Jordan et al. 1972; Kielak et al. 2013) amendment studies. Increases in the abundance of species of Bacteroidetes (Debode et al. 2016), Acidobacteria, and Gemmatimonadetes (Mazzola et al. 2015) in amended soils did not occur in our study. Examining differential abundance of individual sequence variants between amended and unamended soils, we found that 258 sequence variants were enriched in amended soils, including 83 variants that belonged to genera known for their antagonism against fungi and, thus, may represent antifungal antagonists. These consisted of species of Chitinophaga and Streptomyces that were also enriched in Brassica seed meal (Mazzola et al. 2015) or rice bran-induced soil communities (Tomihama et al. 2016); Achromobacter, a genus related to Burkholderia that contains the fungal antagonist Burkholderia gladioli (Raupach and Kloepper 1998) and was enriched in the rhizosphere of apple in Brassica seed meal-amended soil (Mazzola et al. 2015); Pseudoxanthomonas and Stenotrophomonas of the family Xanthomonadaceae, for which increased abundance was documented in rice bran-induced soil communities, as was for Bacillus (Tomihama et al. 2016); Azospirillum, Streptomyces, and unknown genera in the family Oxalobacteraceae that were enriched in chitin-amended soil (Cretoiu et al. 2013; Debode et al. 2016); as well as other genera with antifungal antagonists, including Pseudomonas.

Sequence variants from genera of antifungal antagonists were the most abundant, and the most differentially abundant, among

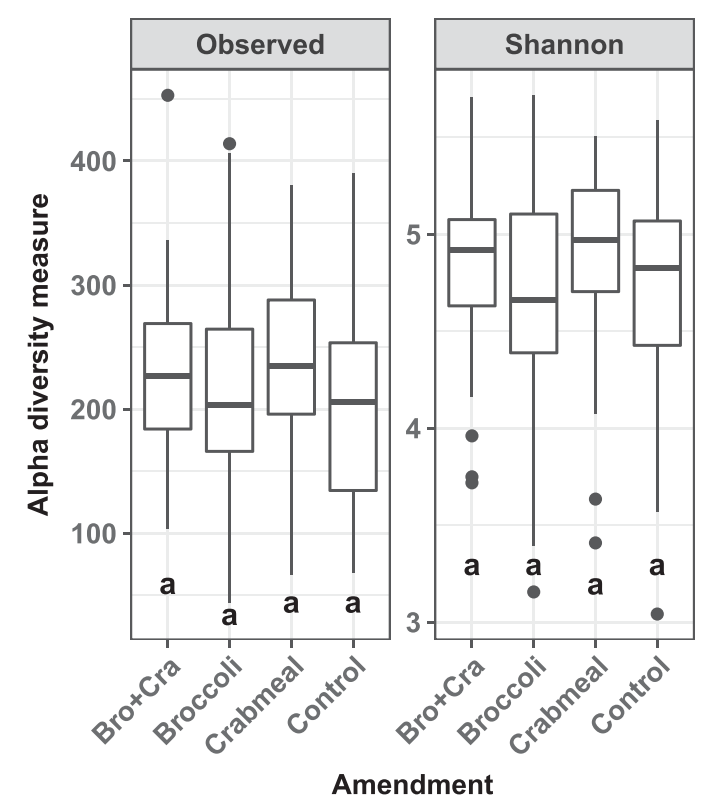

Fig. 5. Boxplots showing the $\alpha$ diversity metrics observed number of sequence variants (richness) and Shannon Index (entropy) for treatments of both soil types combined. The $\alpha$ diversity metrics are indicated in the headers. Samples were rarefied to 1,000 sequences. Significance is indicated by lowercase letters; different letters show significance between treatments (Tukey's honestly significant difference $P<0.05)$. Bro + Cra $=$ broccoli+crabmeal. Number of observations for each diversity metric: $n=152$. 
amendment-enriched variants. A Streptomyces variant accounted for $3.6 \%$ of all sequences in broccoli+crabmeal-treated soil B at time point 1 , and a Pseudomonas variant was up to nearly 2,000 times more abundant in broccoli+crabmeal-amended soil B than in untreated soil at time point 1 . Overall, sequences in genera with antifungal antagonists were significantly more abundant in amended soil, with the highest average abundance of $8.9 \%$ in broccoli+crabmeal treatments. Among amendment-enriched sequence variants, $32 \%$ of all sequences fell into genera containing antifungal antagonists. This suggests that genera with known antifungal antagonists may play a role in Verticillium wilt suppression. However, $34 \%$ of all amendment-enriched variants were not assigned to any known genera, so that other, less well-known groups may also be important. This is supported by the fact that, among the 14 sequence variants whose abundance correlated negatively with disease score at time point 1 and, thus, may be involved in disease reduction, 3 belonged to genera with known antifungal antagonists, 4 belonged to unknown genera, and the remaining 7 were in genera from which antifungal antagonism has not been documented.

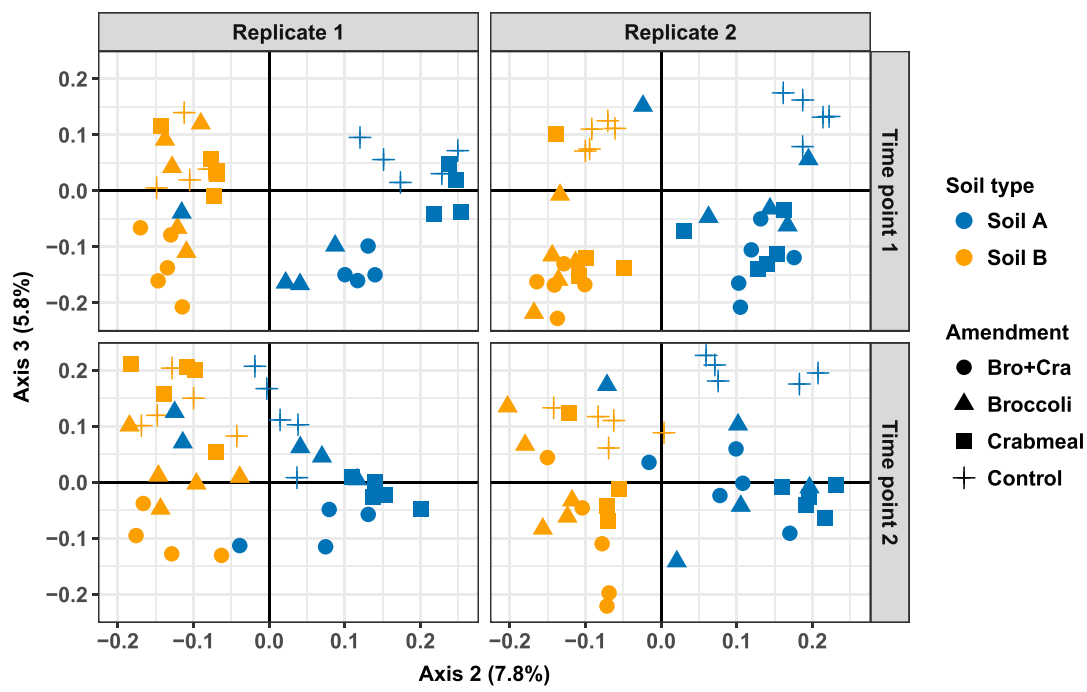

Fig. 6. Principal coordinate analysis ordination plot depicting the relative affinities of the 152 prokaryote communities included in this study. Relative affinity is based on the unweighted UniFrac distance measure. Communities are arranged along axes 2 and 3 and are displayed in different panes depending on experimental replicate and sampling time point, which are indicated in the header and side bar. Plots illustrate that the impact of amendment on communities is similar regardless of soil type, experimental replicate, and time point. Percentage of total variation explained by each axis is provided in the axis titles. Colors show soil type and symbols indicate soil amendments. Bro+Cra $=$ broccoli+crabmeal. Number of observations: $n=152$.
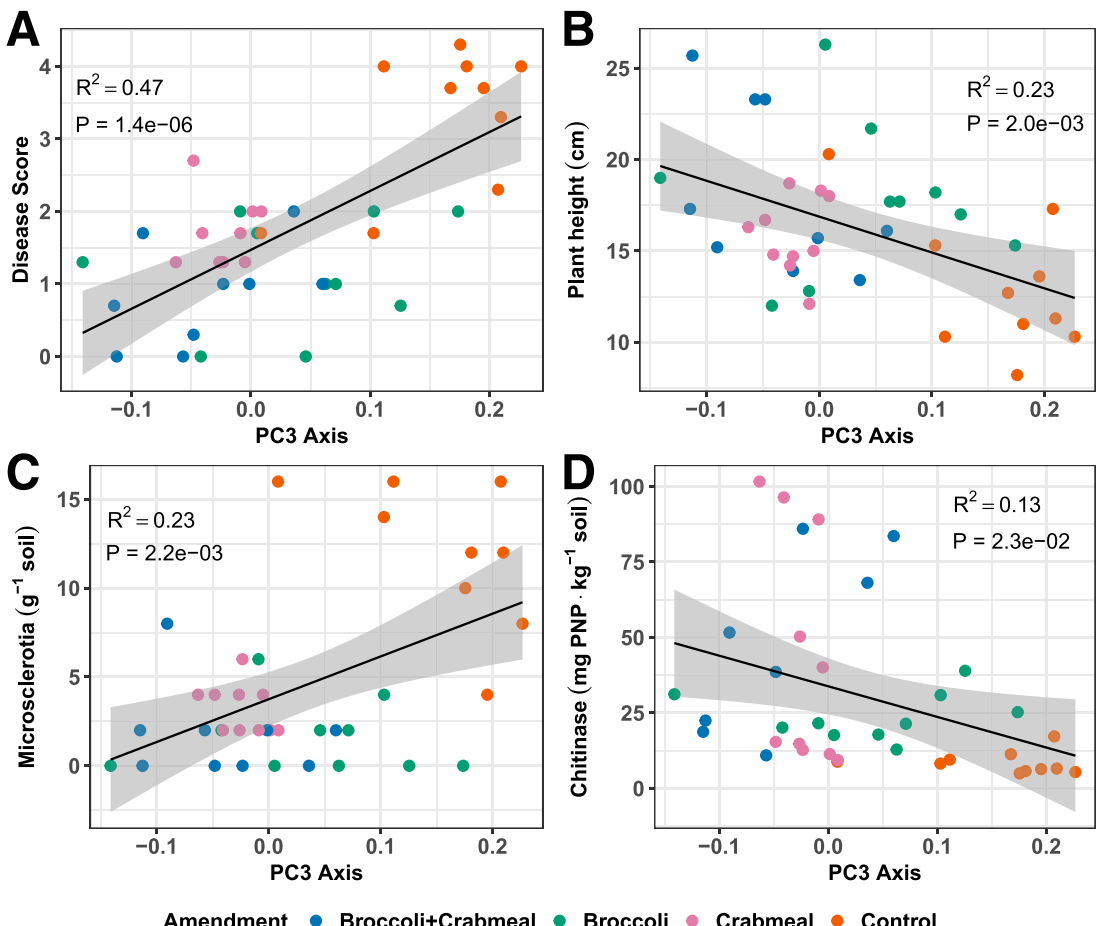

Fig. 7. Correlation plots between prokaryote community structure represented by principal coordinate analysis (PCoA) axis 3 coordinates and response variables. A, Disease score; B, plant height; $\mathbf{C}$, microsclerotia density; and $\mathbf{D}$, chitinase activity. Only soil A samples are included. $R^{2}$ and $P$ values are indicated as insets and colors represent amendments, as explained in the legend. Gray areas are $95 \%$ confidence bands. PCoA axis 3 coordinates were taken from time point 2 of Figure 6. Two outliers were excluded from analyses. Number of observations: A, $n=39 ; \mathrm{B}, n=39 ; \mathrm{C}, n=38$; and $\mathrm{D}, n=38$. 
Analysis of the correlation of sequence variant abundance with disease-related response variables provides information about how the microbiome may be involved in Verticillium wilt reduction. For instance, among the 14 variants whose abundance correlated negatively with disease severity, 3 also correlated positively with plant height, suggesting that they may improve plant vigor; 6 correlated negatively with microsclerotia density and, thus, may degrade microsclerotia; and 1 correlated positively with soil chitinase activity, suggestive of the production of hyphaldegrading chitinases. Based on literature for genera encountered

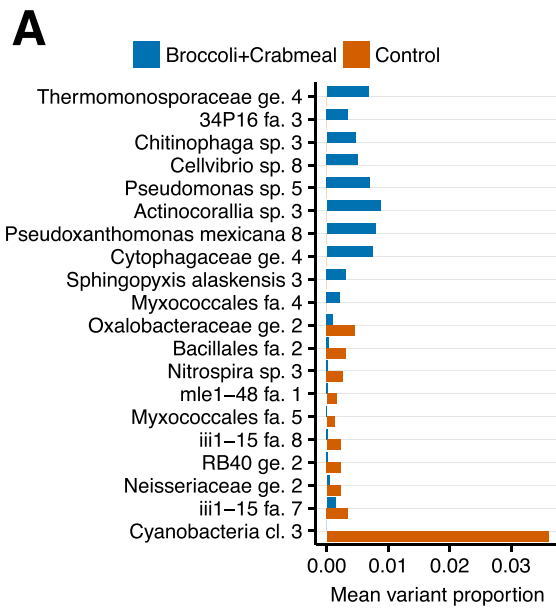

C

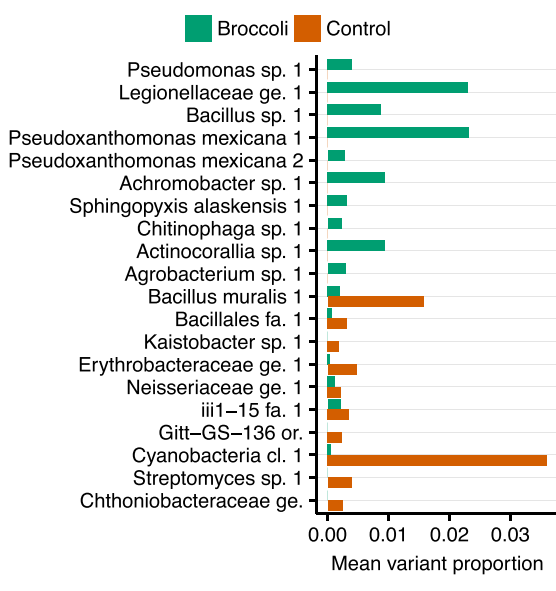

$\mathbf{E}$

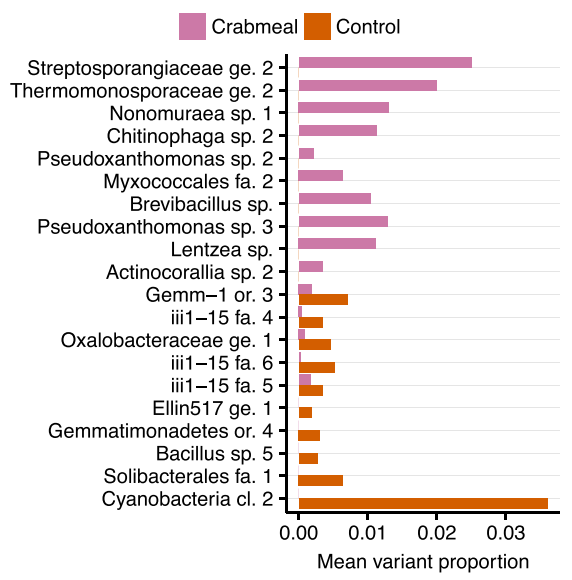

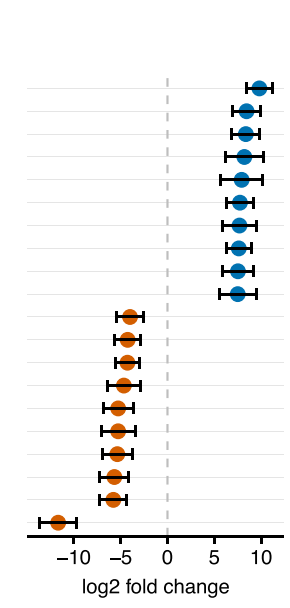

B

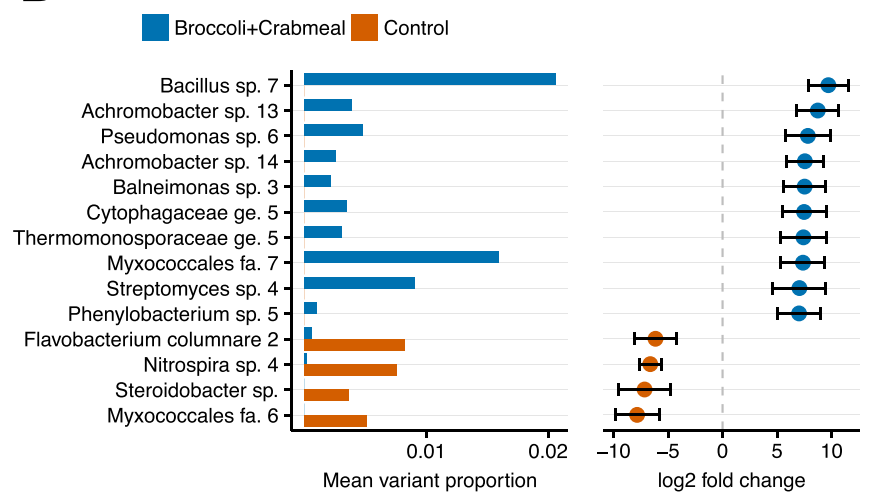

D
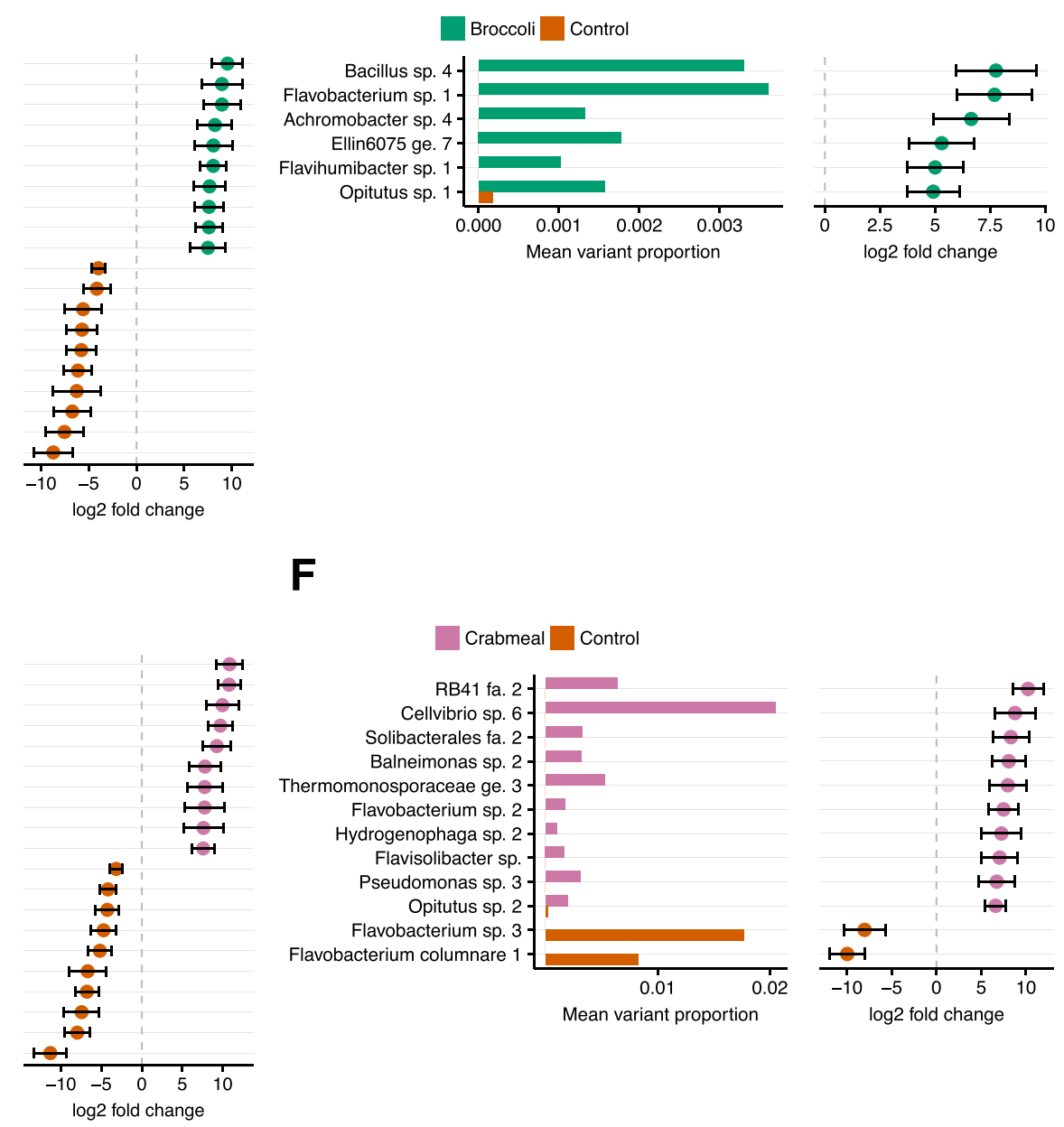

$\mathbf{F}$

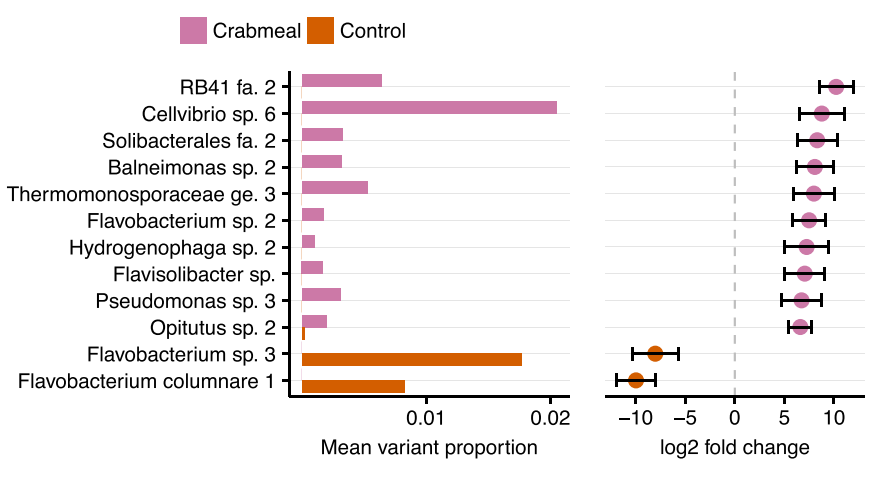

Fig. 8. Grouped bar charts and dot plots of differentially abundant sequence variants between amended and untreated soil samples at time points 1 and 2 for soil A. $\mathbf{A}, \mathbf{C}$, and $\mathbf{E}$, Time point 1 and $\mathbf{B}, \mathbf{D}$, and $\mathbf{F}$, time point 2. Comparisons were broccolitcrabmeal versus control (A and B), broccoli versus control (C and D), and crabmeal versus control (E and F). Mean abundance for each variant is shown on the left in each part and change in abundance on the right. Error bars are standard errors. Changes in abundance and $P$ values are based on DESeq2 normalized read counts. The top 10 enriched variants for amendment and control conditions are included for each comparison $(P<0.05$, with Benjamini-Hochberg correction for multiple comparisons). All variants are shown if fewer than 10 variants were significant. Variant names given on the left in each part consist of the species name, or for unknown species, of the lowest known taxonomic level followed by the abbreviation of the next lower taxonomic level, where $\mathrm{cl} .=$ class, or. $=$ order, fa. $=$ family, ge $=$ genus, and $\mathrm{sp} .=$ species. Numbers following variant names differentiate variants with the same name. 
in this study, protective mechanisms exerted by the amended soil communities may involve antibiosis (Cha et al. 2016; Fravel 1988), cell-wall-degrading enzymes (Renwick et al. 1991), induced systemic resistance (Kloepper et al. 2004; Larkin et al. 1996), iron sequestration (Lemanceau and Alabouvette 1993; Leong 1986), parasitism (El-Tarabily et al. 1997; Olatinwo et al. 2006), and degradation of pathogenicity factors (Schoonbeek et al. 2007). The mechanisms may differ between the broccoli and crabmeal treatments. The current hypothesis is that microbiome-mediated disease reduction in broccoli-amended soils is mainly due to elimination of microsclerotia by lignin-degrading enzymes (Debode et al. 2005; Shetty et al. 2000), and that microbiome-mediated disease reduction in crabmeal-amended soil is principally due to degradation of hyphal cell walls by chitin-degrading enzymes (Cretoiu et al. 2013). A higher microsclerotia density in the crabmeal-amended compared with broccoli-amended soils may have supported this; however, the difference in soil A was not significant and, in soil B, was likely due to incomplete homogenization of the soil. There were bacterial genera capable of degrading lignin represented among all amendmentenriched groups of sequences, including Agrobacterium, Pseudomonas, Streptomyces, and others (Bugg et al. 2011). Thus, microsclerotiadegrading capacity may be promoted by both broccoli and crabmeal amendments. Similarly, sequence variants of the chitin degrader Stenotrophomonas (Hjort et al. 2010) are enriched in broccoli+ crabmeal-, broccoli-, and crabmeal-amended soils, and variants of Chitinophaga, a genus with chitin-degrading capabilities (Sangkhobol and Skerman 1981), are among the top enriched variants in all amended soils. However, the sets of amendment-enriched variants differed between amendment treatments and also between time points. Because we only had four sampling time points in our study, we did not investigate changes of the microbiome over time.

Beneficial microbes often show promise for disease reduction at the experimental stage in the greenhouse (El-Tarabily et al. 2000;

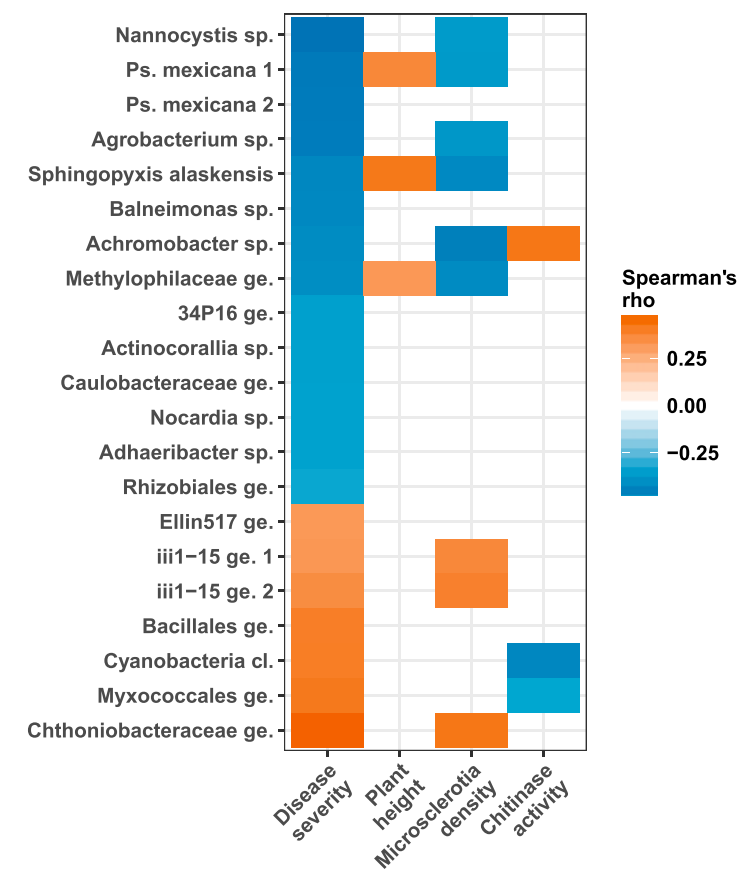

Fig. 9. Heatmap showing correlation based on Spearman's rho between sequence variant abundance and disease score, plant height, microsclerotia density, and soil chitinase activity for both soil types combined. Only the 21 amendment-enriched variants with significant correlation of abundance with disease score at time point 1 were included $(P<0.05$, with BenjaminiHochberg correction for multiple comparisons). Taxonomic names for the variants are given on the left. Abbreviation: Ps. = Pseudoxanthomonas. Response variables are on the X-axis. Colors reflect Spearman's rho as indicated on the right; absence of a colored box indicates lack of significance. Variants are ordered by negative Spearman's rho values for disease severity.
Kamil et al. 2007) or even in field trials (Kim et al. 2008) but, whereas soil organic and mineral amendments are commonly applied in the Salinas Valley to lower disease pressure (Campbell et al. 1985; Myers and Campbell 1985; Subbarao et al. 1999), there has been little promise for microbial formulations to reduce disease and increase plant vigor (Bell et al. 1998a,b). Our study points to potential candidates for formulation as a biocontrol agent, and many of those include relatives of known antifungal antagonists, relatives of groups not known to function as antifungal agents, as well as other groups that are enriched in amended, diseasesuppressive soil but are only distantly related to known species. This last group includes the $34 \%$ of amendment-enriched variants that do not belong to any established genera and have generally not been cultured, which is a prerequisite for effective studies and formulation as biocontrol products. What is encouraging is that a recent study of the Arabidopsis microbiome generated almost 8,000 bacterial cultures, and found that the cultures represented most taxonomic families that were reproducibly detected by DNA sequencing (Bai et al. 2015), thereby suggesting that many of the plant-associated microbes are culturable, as opposed to microbes as a whole (Ward et al. 1990). It is also encouraging that the soils used for this study have been subjected to half a century of methyl bromidechloropicrin soil fumigation (Pegg 1984), repeated monocultures of lettuce and strawberry (Chellemi et al. 2016; Pegg 1984), and copious amounts of synthetic fertilizers (Smukler et al. 2008), and yet the application of broccoli and crabmeal amendments transformed Verticillium wilt-conducive soil to Verticillium wilt-suppressive soil. Our study shows that prokaryote antagonists of plant pathogens can thrive in soil despite prior land management practices, and that their populations are enhanced through addition of organic substrates. Future research will focus on overcoming challenges with resuscitating indigenous beneficial soil microbiota through systemsbased crop and land management practices (Bender et al. 2016; Chellemi et al. 2016), and on the development and deployment of synthetic microbiomes to decrease plant diseases and increase plant vigor (Lebeis et al. 2015; Mueller and Sachs 2015).

\section{ACKNOWLEDGMENTS}

We thank R. Marchebout, S. Gurung, D. Short, and A. Putman, University of California-Davis (UC Davis), and B. Calderon, Driscolls, for help in the greenhouse and laboratory; R. Bostock, Department of Plant Pathology, UC Davis, for providing space in Davis; the Bostock Lab and K. Aram, R. Choudhury, and N. Maharaj for valuable feedback; L. Bijnens, Johnson \& Johnson, for comments on early versions of this work; and The Davis R Users' Group and M. Levy, Department of Environmental Science and Policy, UC Davis, for an introduction to R. Funding was provided by the United States Department of Agriculture National Institute for Food and Agriculture (grant number 2014-04878), the California Department of Pesticide Regulations (grant number 15-PML-R003), and the California Leafy Greens Board.

\section{LITERATURE CITED}

Adhikari, T. B., Joseph, C. M., Yang, G., Phillips, D. A., and Nelson, L. M. 2001. Evaluation of bacteria isolated from rice for plant growth promotion and biological control of seedling disease of rice. Can. J. Microbiol. 47: 916-924.

Ahmed, A. S., Ezziyyani, M., Sánchez, C. P., and Candela, M. E. 2003. Effect of chitin on biological control activity of Bacillus spp. and Trichoderma harzianum against root rot disease in pepper (Capsicum annuum) plants. Eur. J. Plant Pathol. 109:633-637.

Alwathnani, H. A., and Perveen, K. 2014. Biological control of Fusarium wilt of tomato by antagonist fungi and cyanobacteria. Afr. J. Biotechnol. 11: 1100-1105.

Anonymous. 2016a. Monterey County 2015 Crop Report. County of Monterey Agricultural Commissioner, Salinas, CA.

Anonymous. 2016b. Santa Cruz County 2014 Crop Report. Office of the Agricultural Commissioner, Watsonville, CA. 
Atallah, Z. K., Hayes, R. J., and Subbarao, K. V. 2011. Fifteen years of Verticillium wilt of lettuce in America's salad bowl: A tale of immigration, subjugation, and abatement. Plant Dis. 95:784-792.

Bai, Y., Müller, D. B., Srinivas, G., Garrido-Oter, R., Potthoff, E., Rott, M., Dombrowski, N., Münch, P. C., Spaepen, S., and Remus-Emsermann, M. 2015. Functional overlap of the Arabidopsis leaf and root microbiota. Nature 528:364-369.

Bailey, K. L., and Lazarovits, G. 2003. Suppressing soil-borne diseases with residue management and organic amendments. Soil Tillage Res. 72:169-180.

Bell, A. A., Hubbard, J. C., Liu, L., Davis, R. M., and Subbarao, K. V. 1998a. Effects of chitin and chitosan on the incidence and severity of Fusarium yellows of celery. Plant Dis. 82:322-328.

Bell, A. A., Liu, L., Reidy, B., Davis, R. M., and Subbarao, K. V. 1998 b. Mechanisms of subsurface drip irrigation-mediated suppression of lettuce drop caused by Sclerotinia minor. Phytopathology 88:252-259.

Bender, S. F., Wagg, C., and van der Heijden, M. G. A. 2016. An underground revolution: Biodiversity and soil ecological engineering for agricultural sustainability. Trends Ecol. Evol. 31:440-452.

Berg, G., Fritze, A., Roskot, N., and Smalla, K. 2001. Evaluation of potential biocontrol rhizobacteria from different host plants of Verticillium dahliae Kleb. J. Appl. Microbiol. 91:963-971.

Berg, G., Opelt, K., Zachow, C., Lottmann, J., Götz, M., Costa, R., and Smalla, K. 2006. The rhizosphere effect on bacteria antagonistic towards the pathogenic fungus Verticillium differs depending on plant species and site. FEMS Microbiol. Ecol. 56:250-261.

Bibi, F., Yasir, M., Song, G.-C., Lee, S.-Y., and Chung, Y.-R. 2012. Diversity and characterization of endophytic bacteria associated with tidal flat plants and their antagonistic effects on oomycetous plant pathogens. Plant Pathol. J. 28:20-31.

Bonanomi, G., Antignani, V., Capodilupo, M., and Scala, F. 2010. Identifying the characteristics of organic soil amendments that suppress soilborne plant diseases. Soil Biol. Biochem. 42:136-144.

Bugg, T. D. H., Ahmad, M., Hardiman, E. M., and Rahmanpour, R. 2011. Pathways for degradation of lignin in bacteria and fungi. Nat. Prod. Rep. 28:1883-1896.

Bull, C. T., Shetty, K. G., and Subbarao, K. V. 2002. Interactions between myxobacteria, plant pathogenic fungi, and biocontrol agents. Plant Dis. 86:889-896.

Butler, M. J., and Day, A. W. 1998. Destruction of fungal melanins by ligninases of Phanerochaete chrysosporium and other white rot fungi. Int. J. Plant Sci. 159:989-995.

Callahan, B. J., McMurdie, P. J., Rosen, M. J., Han, A. W., Johnson, A. J. A., and Holmes, S. P. 2016. DADA2: High-resolution sample inference from Illumina amplicon data. Nat. Methods 13:581-583.

Campbell, R. N., Greathead, A. S., Myers, D. F., and De Boer, G. J. 1985. Factors related to control of clubroot of crucifers in the Salinas Valley of California. Phytopathology 75:665-670.

Caporaso, J. G., Bittinger, K., Bushman, F. D., DeSantis, T. Z., Andersen, G. L., and Knight, R. 2010. PyNAST: A flexible tool for aligning sequences to a template alignment. Bioinformatics 26:266-267.

Cha, J.-Y., Han, S., Hong, H.-J., Cho, H., Kim, D., Kwon, Y., Kwon, S.-K., Crüsemann, M., Lee, Y. B., and Kim, J. F. 2016. Microbial and biochemical basis of a Fusarium wilt-suppressive soil. ISME J. 10:119-129.

Chaiharn, M., Chunhaleuchanon, S., and Lumyong, S. 2009. Screening siderophore producing bacteria as potential biological control agent for fungal rice pathogens in Thailand. World J. Microb. Biot. 25:1919-1928.

Chakraborty, U., and Chakraborty, B. N. 1989. Interaction of Rhizobium leguminosarum and Fusarium solani f. sp. pisi on pea affecting disease development and phytoalexin production. Can. J. Bot. 67:1698-1701.

Chakraborty, U., and Purkayastha, R. P. 1984. Role of rhizobitoxine in protecting soybean roots from Macrophomina phaseolina infection. Can. J. Microbiol. 30:285-289.

Chandel, S., Allan, E. J., and Woodward, S. 2010. Biological control of Fusarium oxysporum f. sp. lycopersici on tomato by Brevibacillus brevis. J. Phytopathol. 158:470-478.

Chellemi, D. O., Gamliel, A., Katan, J., and Subbarao, K. V. 2016. Development and deployment of systems-based approaches for the management of soilborne plant pathogens. Phytopathology 106:216-225.

Chellemi, D. O., and Lazarovits, G. 2002. Effect of organic fertilizer applications on growth, yield and pests of vegetable crops. Proc. Fla. State Hortic. Soc. 115:315-321.

Chellemi, D. O., Wu, T., Graham, J. H., and Church, G. 2012. Biological impact of divergent land management practices on tomato crop health. Phytopathology 102:597-608.

Chen, W.-Q., Morgan, D. P., Felts, D. G., and Michailides, T. J. 2003. Antagonism of Paenibacillus lentimorbus to Botryosphaeria dothidea and biological control of panicle and shoot blight of pistachio. Plant Dis. 87:359-365.

Chernin, L., Ismailov, Z., Haran, S., and Chet, I. 1995. Chitinolytic Enterobacter agglomerans antagonistic to fungal plant pathogens. Appl. Environ. Microbiol. 61:1720-1726.
Coombs, J. T., Michelsen, P. P., and Franco, C. M. M. 2004. Evaluation of endophytic actinobacteria as antagonists of Gaeumannomyces graminis var. tritici in wheat. Biol. Control 29:359-366.

Cordero-Ramírez, J. D., López-Rivera, R., Figueroa-Lopez, A. M., Mancera-López, M. E., Martínez-Álvarez, J. C., Apodaca-Sánchez, M. Á., and Maldonado-Mendoza, I. E. 2013. Native soil bacteria isolates in Mexico exhibit a promising antagonistic effect against Fusarium oxysporum f. sp. radicis-lycopersici. J. Basic Microbiol. 53:1-10.

Cretoiu, M. S., Kielak, A. M., Schluter, A., and van Elsas, J. D. 2014. Bacterial communities in chitin-amended soil as revealed by $16 \mathrm{~S}$ rRNA gene based pyrosequencing. Soil Biol. Biochem. 76:5-11.

Cretoiu, M. S., Korthals, G. W., Visser, J. H., and van Elsas, J. D. 2013. Chitin amendment increases soil suppressiveness toward plant pathogens and modulates the actinobacterial and oxalobacteraceal communities in an experimental agricultural field. Appl. Environ. Microbiol. 79:5291-5301.

De Boer, W., Wagenaar, A.-M., Gunnewiek, P. J. A. K., and Van Veen, J. A. 2007. In vitro suppression of fungi caused by combinations of apparently non-antagonistic soil bacteria. FEMS Microbiol. Ecol. 59:177-185.

Debode, J., Clewes, E., De Backer, G., and Höfte, M. 2005. Lignin is involved in the reduction of Verticillium dahliae var. longisporum inoculum in soil by crop residue incorporation. Soil Biol. Biochem. 37:301-309.

Debode, J., De Tender, C., Soltaninejad, S., Van Malderghem, C., Haegeman, A., Van der Linden, I., Cottyn, B., Heyndrickx, M., and Maes, M. 2016. Chitin mixed in potting soil alters lettuce growth, the survival of zoonotic bacteria on the leaves and associated rhizosphere microbiology. Front. Microbiol. 7:565.

de Mendiburu, F. 2016. Agricolae: Statistical Procedures for Agricultural Research. R Package, version 1.2-4. https://cran.r-project.org/web/packages/ agricolae/index.html

DeSantis, T. Z., Hugenholtz, P., Larsen, N., Rojas, M., Brodie, E. L., Keller, K., Huber, T., Dalevi, D., Hu, P., and Andersen, G. L. 2006. Greengenes, a chimera-checked 16S rRNA gene database and workbench compatible with ARB. Appl. Environ. Microbiol. 72:5069-5072.

Domenech, J., Reddy, M. S., Kloepper, J. W., Ramos, B., and Gutierrez-Mañero, J. 2006. Combined application of the biological product LS213 with Bacillus, Pseudomonas or Chryseobacterium for growth promotion and biological control of soil-borne diseases in pepper and tomato. BioControl 51:245-258.

Duniway, J. M. 2002. Status of chemical alternatives to methyl bromide for pre-plant fumigation of soil. Phytopathology 92:1337-1343.

Dutta, B., and Isaac, I. 1979. Effects of organic amendments to soil on the rhizosphere microflora of antirrhinum infected with Verticillium dahliae Kleb. Plant Soil 53:99-103.

Edgar, R. C. 2010. Search and clustering orders of magnitude faster than BLAST. Bioinformatics 26:2460-2461.

El-Banna, N. M. 2007. Antifungal activity of Comamonas acidovorans isolated from water pond in south Jordan. Afr. J. Biotechnol. 6:2216-2219.

Elson, M. K., Schisler, D. A., and Bothast, R. J. 1997. Selection of microorganisms for biological control of silver scurf (Helminthosporium solani) of potato tubers. Plant Dis. 81:647-652.

El-Tarabily, K. A. 2003. An endophytic chitinase-producing isolate of Actinoplanes missouriensis, with potential for biological control of root rot of lupin caused by Plectosporium tabacinum. Aust. J. Bot. 51:257-266.

El-Tarabily, K. A., Hardy, G. E., Sivasithamparam, K., Hussein, A. M., and Kurtböke, D. 1997. The potential for the biological control of cavity-spot disease of carrots, caused by Pythium coloratum, by streptomycete and nonstreptomycete actinomycetes. New Phytol. 137:495-507.

El-Tarabily, K. A., Soliman, M. H., Nassar, A. H., Al-Hassani, H. A., Sivasithamparam, K., McKenna, F., and Hardy, G. E. S. J. 2000. Biological control of Sclerotinia minor using a chitinolytic bacterium and actinomycetes. Plant Pathol. 49:573-583.

Erdogan, O., and Benlioglu, K. 2010. Biological control of Verticillium wilt on cotton by the use of fluorescent Pseudomonas spp. under field conditions. Biol. Control 53:39-45.

Essghaier, B., Fardeau, M.-L., Cayol, J.-L., Hajlaoui, M. R., Boudabous, A., Jijakli, H., and Sadfi-Zouaoui, N. 2009. Biological control of grey mould in strawberry fruits by halophilic bacteria. J. Appl. Microbiol. 106:833-846.

Evans, G., and McKeen, C. D. 1975. Influence of crops on numbers of microsclerotia of Verticillium dahliae in soils and the development of wilt in southwestern Ontario. Can. J. Plant Sci. 55:827-834.

Fox, J., and Weisberg, S. 2011. An R Companion to Applied Regression. Sage, Thousand Oaks, CA.

Fravel, D. R. 1988. Role of antibiosis in the biocontrol of plant diseases. Annu. Rev. Phytopathol. 26:75-91.

Friebertshauser, G. E., and DeVay, J. E. 1982. Differential effects of the defoliating and nondefoliating pathotypes of Verticillium dahliae upon the growth and development of Gossypium hirsutum. Phytopathology 72: 872-877.

Fudou, R., Iizuka, T., and Yamanaka, S. 2001. Haliangicin, a novel antifungal metabolite produced by a marine myxobacterium. J. Antibiot. 54:149-152. 
Garbeva, P., Van Veen, J. A., and Van Elsas, J. D. 2004. Microbial diversity in soil: Selection of microbial populations by plant and soil type and implications for disease suppressiveness. Annu. Rev. Phytopathol. 42:243-270.

Green, R. J., and Papavizas, G. C. 1968. Effect of carbon source, carbon to nitrogen ratios, and organic amendments on survival of propagules of Verticillium albo-atrum in soil. Phytopathology 58:567-570.

Haenseler, C. M. 1928. Effect of soil reaction on Verticillium wilt of eggplant. Annu. Rep. N. J. State Agric. Res. Stn. 49:267-273.

Hallmann, J., Rodríguez-Kábana, R., and Kloepper, J. W. 1999. Chitinmediated changes in bacterial communities of the soil, rhizosphere and within roots of cotton in relation to nematode control. Soil Biol. Biochem. 31:551-560.

Henis, Y., Sneh, B., and Katan, J. 1967. Effect of organic amendments on Rhizoctonia and accompanying microflora in soil. Can. J. Microbiol. 13: 643-650.

Herlemann, D. P. R., Labrenz, M., Jürgens, K., Bertilsson, S., Waniek, J. J., and Andersson, A. F. 2011. Transitions in bacterial communities along the $2000 \mathrm{~km}$ salinity gradient of the Baltic Sea. ISME J. 5:1571-1579.

Hjort, K., Bergström, M., Adesina, M. F., Jansson, J. K., Smalla, K., and Sjöling, S. 2010. Chitinase genes revealed and compared in bacterial isolates, DNA extracts and a metagenomic library from a phytopathogensuppressive soil. FEMS Microbiol. Ecol. 71:197-207.

Hoitink, H. A. J., and Boehm, M. J. 1999. Biocontrol within the context of soil microbial communities: A substrate-dependent phenomenon. Annu. Rev. Phytopathol. 37:427-446.

Hope, R. M. 2013. Rmisc: Ryan Miscellaneous. R Package, version 1.5. https://cran.r-project.org/web/packages/Rmisc/index.html

Inderbitzin, P., Bostock, R. M., Davis, R. M., Usami, T., Platt, H. W., and Subbarao, K. V. 2011. Phylogenetics and taxonomy of the fungal vascular wilt pathogen Verticillium, with the descriptions of five new species. PLoS One 6:e28341.

Inderbitzin, P., and Subbarao, K. V. 2014. Verticillium systematics and evolution: How confusion impedes Verticillium wilt management and how to resolve it. Phytopathology 104:564-574.

Inderiati, S., and Franco, C. M. 2008. Isolation and identification of endophytic actinomycetes and their antifungal activity. J. Biotechnol. Res. Trop. Reg. 1:1-6.

Jacquiod, S., Franqueville, L., Cécillon, S., Vogel, T. M., and Simonet, P. 2013. Soil bacterial community shifts after chitin enrichment: An integrative metagenomic approach. PLoS One 8:e79699.

Jordan, V. W. L., Sneh, B., and Eddy, B. P. 1972. Influence of organic soil amendments on Verticillium dahliae and on the microbial composition of the strawberry rhizosphere. Ann. Appl. Biol. 70:139-148.

Kabir, Z., Bhat, R. G., and Subbarao, K. V. 2004. Comparison of media for recovery of Verticillium dahliae from soil. Plant Dis. 88:49-55.

Kamil, Z., Saleh, M., and Moustafa, S. 2007. Isolation and identification of rhizosphere soil chitinolytic bacteria and their potential in antifungal biocontrol. GJMS 2:57-66.

Kielak, A. M., Cretoiu, M. S., Semenov, A. V., Sørensen, S. J., and van Elsas, J. D. 2013. Bacterial chitinolytic communities respond to chitin and $\mathrm{pH}$ alteration in soil. Appl. Environ. Microbiol. 79:263-272.

Kim, B. S., Moon, S. S., and Hwang, B. K. 2000. Structure elucidation and antifungal activity of an anthracycline antibiotic, daunomycin, isolated from Actinomadura roseola. J. Agric. Food Chem. 48:1875-1881.

Kim, Y. C., Jung, H., Kim, K. Y., and Park, S. K. 2008. An effective biocontrol bioformulation against Phytophthora blight of pepper using growth mixtures of combined chitinolytic bacteria under different field conditions. Eur. J. Plant Pathol. 120:373-382.

Klindworth, A., Pruesse, E., Schweer, T., Peplies, J., Quast, C., Horn, M., and Glöckner, F. O. 2012. Evaluation of general 16S ribosomal RNA gene PCR primers for classical and next-generation sequencing-based diversity studies. Nucleic Acids Res. 41:e1.

Kloepper, J. W., Ryu, C.-M., and Zhang, S. 2004. Induced systemic resistance and promotion of plant growth by Bacillus spp. Phytopathology 94:1259-1266.

Korthals, G. W., Thoden, T. C., Van den Berg, W., and Visser, J. H. M. 2014. Longterm effects of eight soil health treatments to control plant-parasitic nematodes and Verticillium dahliae in agro-ecosystems. Appl. Soil Ecol. 76:112-123.

Kundim, B. A., Itou, Y., Sakagami, Y., Fudou, R., Iizuka, T., Yamanaka, S., and Ojika, M. 2003. New haliangicin isomers, potent antifungal metabolites produced by a marine myxobacterium. J. Antibiot. 56:630-638.

Kwok, O. C. H., Fahy, P. C., Hoitink, H. A. J., and Kuter, G. A. 1987. Interactions between bacteria and Trichoderma hamatum in suppression of Rhizoctonia damping-off in bark compost media. Phytopathology 77:1206-1212.

Larkin, R. P., Hopkins, D. L., and Martin, F. N. 1996. Suppression of Fusarium wilt of watermelon by non-pathogenic Fusarium oxysporum and other microorganisms recovered from a disease-suppressive soil. Phytopathology 86:812-819.

Lazarovits, G., and Subbarao, K. V. 2009. Challenges in controlling Verticillium wilt by the use of nonchemical methods. Pages 247-264 in: Recent
Developments in Management of Plant Diseases, Vol. 1. U. Gisi, I. Chet, and M. L. Gullino, eds. Springer, Dordrecht, the Netherlands.

Lebeis, S. L., Paredes, S. H., Lundberg, D. S., Breakfield, N., Gehring, J., McDonald, M., Malfatti, S., Del Rio, T. G., Jones, C. D., and Tringe, S. G. 2015. Salicylic acid modulates colonization of the root microbiome by specific bacterial taxa. Science 349:860-864

Lee, J. Y., and Hwang, B. K. 2002. Diversity of antifungal actinomycetes in various vegetative soils of Korea. Can. J. Microbiol. 48:407-417.

Lemanceau, P., and Alabouvette, C. 1993. Suppression of Fusarium wilts by fluorescent pseudomonads: Mechanisms and applications. Biocontrol Sci. Technol. 3:219-234.

Leong, J. 1986. Siderophores: Their biochemistry and possible role in the biocontrol of plant pathogens. Annu. Rev. Phytopathol. 24:187-209.

Li, S., Jochum, C. C., Yu, F., Zaleta-Rivera, K., Du, L., Harris, S. D., and Yuen, G. Y. 2008. An antibiotic complex from Lysobacter enzymogenes strain C3: Antimicrobial activity and role in plant disease control. Phytopathology 98 : 695-701.

Liu, C. H., Chen, X., Liu, T. T., Lian, B., Gu, Y., Caer, V., Xue, Y. R., and Wang, B. T. 2007. Study of the antifungal activity of Acinetobacter baumannii LCH001 in vitro and identification of its antifungal components. Appl. Microbiol. Biotechnol. 76:459-466.

Love, M. I., Huber, W., and Anders, S. 2014. Moderated estimation of fold change and dispersion for RNA-seq data with DESeq2. Genome Biol. 15: 550 .

Lozupone, C., and Knight, R. 2005. UniFrac: A new phylogenetic method for comparing microbial communities. Appl. Environ. Microbiol. 71:8228-8235.

Lugtenberg, B., and Kamilova, F. 2009. Plant-growth-promoting rhizobacteria. Annu. Rev. Microbiol. 63:541-556.

Mangiafico, S. S. 2015. An R Companion for the Handbook of Biological Statistics, Version 1.09d.

Mansoor, A., Seema, D., Abdul-Khaliq, Kumar, S. S., Abdul, S., and Mahesh Kumar, G. 2012. A promising strain of Streptomyces sp. with agricultural traits for growth promotion and disease management. Indian J. Exp. Biol. 50:559-568.

Matsuda, Y., Yuichiro, I., Shinogi, T., Kakutani, K., Nonomura, T., and Toyoda, H. 2001. In vitro suppression of mycelial growth of Fusarium oxysporum by extracellular chitosanase of Sphingobacterium multivorum and cloning of the chitosanase gene csnSM1. J. Gen. Plant Pathol. 67: 318-324.

Mayton, H. S., Olivier, C., Vaughn, S. F., and Loria, R. 1996. Correlation of fungicidal activity of Brassica species with allyl isothiocyanate production in macerated leaf tissue. Phytopathology 86:267-271.

Mazzola, M., Hewavitharana, S. S., and Strauss, S. L. 2015. Brassica seed meal soil amendments transform the rhizosphere microbiome and improve apple production through resistance to pathogen reinfestation. Phytopathology 105:460-469.

McDonald, D., Price, M. N., Goodrich, J., Nawrocki, E. P., DeSantis, T. Z., Probst, A., Andersen, G. L., Knight, R., and Hugenholtz, P. 2012. An improved Greengenes taxonomy with explicit ranks for ecological and evolutionary analyses of bacteria and archaea. ISME J. 6:610-618.

McLoughlin, T. J., Quinn, J. P., Bettermann, A., and Bookland, R. 1992. Pseudomonas cepacia suppression of sunflower wilt fungus and role of antifungal compounds in controlling the disease. Appl. Environ. Microbiol. 58:1760-1763

McMurdie, P. J., and Holmes, S. 2013. phyloseq: An R package for reproducible interactive analysis and graphics of microbiome census data. PLoS One 8:e61217.

Melnick, R. L., Suárez, C., Bailey, B. A., and Backman, P. A. 2011. Isolation of endophytic endospore-forming bacteria from Theobroma cacao as potential biological control agents of cacao diseases. Biol. Control 57:236-245.

Mmbaga, M. T., Sauve, R. J., and Mrema, F. A. 2008. Identification of microorganisms for biological control of powdery mildew in Cornus florida. Biol. Control 44:67-72.

Moretti, M., Gilardi, G., Gullino, M. L., and Garibaldi, A. 2008. Biological control potential of Achromobacter xylosoxydans for suppressing Fusarium wilt of tomato. Int. J. Bot. 4:369-375.

Morrissey, R. F., Dugan, E. P., and Koths, J. S. 1976. Chitinase production by an Arthrobacter sp. lysing cells of Fusarium roseum. Soil Biol. Biochem. 8:23-28.

Mueller, U. G., and Sachs, J. L. 2015. Engineering microbiomes to improve plant and animal health. Trends Microbiol. 23:606-617.

Muzammil, S., Graillon, C., Saria, R., Mathieu, F., Lebrihi, A., and Compant, S. 2014. The Saharan isolate Saccharothrix algeriensis NRRL B-24137 induces systemic resistance in Arabidopsis thaliana seedlings against Botrytis cinerea. Plant Soil 374:423-434.

Myers, D. F., and Campbell, R. N. 1985. Lime and the control of clubroot of crucifers: Effects of $\mathrm{pH}$, calcium, magnesium, and their interactions. Phytopathology 75:670-673.

Njoroge, S. M., Kabir, Z., Martin, F. N., Koike, S. T., and Subbarao, K. V. 2009. Comparison of crop rotation for Verticillium wilt management and 
effect on Pythium species in conventional and organic strawberry production. Plant Dis. 93:519-527.

Oksanen, J., Blanchet, F. G., Friendly, M., Kindt, R., Legendre, P., McGlinn, D., Minchin, P. R., O’Hara, R. B., Simpson, G. L., Solymos, P., Stevens, M. H. H., Szoecs, E., and Wagner, H. 2016. vegan: Community Ecology Package. https://cran.r-project.org/web/packages/vegan/index.html

Olatinwo, R., Yin, B., Becker, J. O., and Borneman, J. 2006. Suppression of the plant-parasitic nematode Heterodera schachtii by the fungus Dactylella oviparasitica. Phytopathology 96:111-114.

Parham, J. A., and Deng, S. P. 2000. Detection, quantification and characterization of $\beta$-glucosaminidase activity in soil. Soil Biol. Biochem. 32:1183-1190.

Pegg, G. F. 1984. The impact of Verticillium diseases in agriculture. Phytopathol. Mediterr. 23:176-192.

Pegg, G. F., and Brady, B. L., eds. 2002. Verticillium Wilts. CABI Publishing, Wallingford, Oxon, UK.

Pereira, P., Nesci, A., and Etcheverry, M. 2007. Effects of biocontrol agents on Fusarium verticillioides count and fumonisin content in the maize agroecosystem: Impact on rhizospheric bacterial and fungal groups. Biol. Control 42:281-287.

Price, M. N., Dehal, P. S., and Arkin, A. P. 2010. FastTree 2-Approximately maximum-likelihood trees for large alignments. PLoS One 5:e9490.

Raupach, G. S., and Kloepper, J. W. 1998. Mixtures of plant growth-promoting rhizobacteria enhance biological control of multiple cucumber pathogens. Phytopathology 88:1158-1164.

R Core Team. 2015. RStudio: Integrated Development for R. RStudio, Inc., Boston.

R Core Team. 2017. R: A Language and Environment for Statistical Computing. R Foundation for Statistical Computing, Vienna.

Renwick, A., Campbell, R., and Coe, S. 1991. Assessment of in vivo screening systems for potential biocontrol agents of Gaeumannomyces graminis. Plant Pathol. 40:524-532.

Rodriguez-Kabana, R., Morgan-Jones, G., and Chet, I. 1987. Biological control of nematodes: Soil amendments and microbial antagonists. Plant Soil 100:237-247.

Rowe, R. C., and Powelson, M. L. 2002. Potato early dying: Management challenges in a changing production environment. Plant Dis. 86:1184-1193.

Sangkhobol, V., and Skerman, V. B. D. 1981. Chitinophaga, a new genus of chitinolytic myxobacteria. Int. J. Syst. Evol. Microbiol. 31:285-293.

Sarkar, D. 2008. Lattice: Multivariate Data Visualization with R. Springer, New York.

Schoonbeek, H.-j., Jacquat-Bovet, A.-C., Mascher, F., and Métraux, J.-P. 2007. Oxalate-degrading bacteria can protect Arabidopsis thaliana and crop plants against Botrytis cinerea. Mol. Plant-Microbe Interact. 20:1535-1544.

Selvakumar, G., Joshi, P., Nazim, S., Mishra, P. K., Kundu, S., and Gupta, H. S. 2009. Exiguobacterium acetylicum strain 1P (MTCC 8707) a novel bacterial antagonist from the north western Indian Himalayas. World J. Microb. Biot. 25:131-137.

Sharp, R. G. 2013. A review of the applications of chitin and its derivatives in agriculture to modify plant-microbial interactions and improve crop yields. Agronomy 3:757-793.

Shetty, K. G., Subbarao, K. V., Huisman, O. C., and Hubbard, J. C. 2000. Mechanism of broccoli-mediated Verticillium wilt reduction in cauliflower. Phytopathology 90:305-310.

Smukler, S. M., Jackson, L. E., Murphree, L., Yokota, R., Koike, S. T., and Smith, R. F. 2008. Transition to large-scale organic vegetable production in the Salinas Valley, California. Agric. Ecosyst. Environ. 126:168-188.

Spiegel, Y., Cohn, E., and Chet, I. 1986. Use of chitin for controlling plant parasitic nematodes. Plant Soil 95:87-95.

Sturz, A. V., Christie, B. R., and Matheson, B. G. 1998. Associations of bacterial endophyte populations from red clover and potato crops with potential for beneficial allelopathy. Can. J. Microbiol. 44:162-167.

Subbarao, K. V., Hubbard, J. C., Greathead, A. S., and Spencer, G. A. 1997. Verticillium wilt. Pages 26-27 in: Compendium of Lettuce Diseases. R. M. Davis, K. V. Subbarao, R. N. Raid, and E. A. Kurtz, eds. The American Phytopathological Society, St. Paul, MN.

Subbarao, K. V., Hubbard, J. C., and Koike, S. T. 1999. Evaluation of broccoli residue incorporation into field soil for Verticillium wilt control in cauliflower. Plant Dis. 83:124-129.

Subbarao, K. V., Kabir, Z., Martin, F. N., and Koike, S. T. 2007. Management of soilborne diseases in strawberry using vegetable rotations. Plant Dis. 91: 964-972.
Taylor, W. J., and Draughon, F. A. 2001. Nannocystis exedens: A potential biocompetitive agent against Aspergillus flavus and Aspergillus parasiticus. J. Food Prot. 64:1030-1034.

Thomashow, L. S., and Weller, D. M. 1988. Role of a phenazine antibiotic from Pseudomonas fluorescens in biological control of Gaeumannomyces graminis var. tritici. J. Bacteriol. 170:3499-3508.

Tierens, K. F. M. J., Thomma, B. P. H., Brouwer, M., Schmidt, J., Kistner, K., Porzel, A., Mauch-Mani, B., Cammue, B. P. A., and Broekaert, W. F. 2001. Study of the role of antimicrobial glucosinolate-derived isothiocyanates in resistance of Arabidopsis to microbial pathogens. Plant Physiol. 125: 1688-1699.

Tomihama, T., Nishi, Y., Mori, K., Shirao, T., Iida, T., Uzuhashi, S., Ohkuma, M., and Ikeda, S. 2016. Rice bran amendment suppresses potato common scab by increasing antagonistic bacterial community levels in the rhizosphere. Phytopathology 106:719-728.

Tortora, M. L., Díaz-Ricci, J. C., and Pedraza, R. O. 2011a. Protection of strawberry plants (Fragaria ananassa Duch.) against anthracnose disease induced by Azospirillum brasilense. Plant Soil 356:279-290.

Tortora, M. L., Díaz-Ricci, J. C., and Pedraza, R. O. 2011b. Azospirillum brasilense siderophores with antifungal activity against Colletotrichum acutatum. Arch. Microbiol. 193:275-286.

Turnbull, A. L., Liu, Y., and Lazarovits, G. 2012. Isolation of bacteria from the rhizosphere and rhizoplane of potato (Solanum tuberosum) grown in two distinct soils using semi selective media and characterization of their biological properties. Am. J. Potato Res. 89:294-305.

Vallad, G. E., Qin, Q.-M., Grube, R., Hayes, R. J., and Subbarao, K. V. 2006. Characterization of race-specific interactions among isolates of Verticillium dahliae pathogenic on lettuce. Phytopathology 96:1380-1387.

Vida, C., Bonilla, N., de Vicente, A., and Cazorla, F. M. 2016. Microbial profiling of a suppressiveness-induced agricultural soil amended with composted almond shells. Front. Microbiol. 7:4.

Ward, D. M., Weller, R., and Bateson, M. M. 1990. 16S rRNA sequences reveal numerous uncultured microorganisms in a natural community. Nature 345:63-65.

Weller, D. M., Raaijmakers, J. M., Gardener, B. B. M., and Thomashow, L. S. 2002. Microbial populations responsible for specific soil suppressiveness to plant pathogens. Annu. Rev. Phytopathol. 40:309-348.

Werner, J. J., Koren, O., Hugenholtz, P., DeSantis, T. Z., Walters, W. A., Caporaso, J. G., Angenent, L. T., Knight, R., and Ley, R. E. 2012. Impact of training sets on classification of high-throughput bacterial 16s rRNA gene surveys. ISME J. 6:94-103.

Wheeler, M. H., Tolmsoff, W. J., and Meola, S. 1976. Ultrastructure of melanin formation in Verticillium dahliae with (+)-scytalone as a biosynthetic intermediate. Can. J. Microbiol. 22:702-711.

White, J. L. 2013. Methyl bromide primer and timeline. Calif. Agric. 67:121.

Wickham, H. 2009. ggplot2: Elegant Graphics for Data Analysis. Springer Science \& Business Media, New York.

Wickham, H. 2011. The split-apply-combine strategy for data analysis. J. Stat. Softw. 40:1-29.

Wickham, H. 2016. tidyr: Easily Tidy Data with 'spread()' and 'gather()' functions. R Package, version 0.5.1. https://github.com/tidyverse/tidyr

Wickham, H., and Francois, R. 2016. dplyr: A Grammar of Data Manipulation. R Package, version 0.5.0. https://github.com/tidyverse/dplyr

Wilhelm, S. 1951. Effect of various soil amendments on the inoculum potential of the Verticillium wilt fungus. Phytopathology 41:684-690.

Wilhelm, S. 1955. Longevity of the Verticillium wilt fungus in the laboratory and field. Phytopathology 45:180-181.

Wilhelm, S., and Paulus, A. O. 1980. How soil fumigation benefits the California strawberry industry. Plant Dis. 64:264-270.

Xiao, C. L., Subbarao, K. V., Schulbach, K. F., and Koike, S. T. 1998. Effects of crop rotation and irrigation on Verticillium dahliae microsclerotia in soil and wilt in cauliflower. Phytopathology 88:1046-1055.

Yang, J. H., Liu, H. X., Zhu, G. M., Pan, Y. L., Xu, L. P., and Guo, J. H. 2008. Diversity analysis of antagonists from rice-associated bacteria and their application in biocontrol of rice diseases. J. Appl. Microbiol. 104: 91-104.

Yin, C., Hulbert, S. H., Schroeder, K. L., Mavrodi, O., Mavrodi, D., Dhingra, A., Schillinger, W. F., and Paulitz, T. C. 2013. Role of bacterial communities in the natural suppression of Rhizoctonia solani bare patch disease of wheat (Triticum aestivum L.). Appl. Environ. Microbiol. 79: 7428-7438. 